NBSIR 83-2791

\title{
An Acute Inhalation Toxicological Evaluation of Combustion Products From Fire Retarded and Non-Fire Retarded Flexible Polyurethane Foam and Polyester
}

U.S. DEPARTMENT OF COMMERCE

National Bureau of Standards

National Engineering Laboratory

Center for Fire Research

Washington, DC 20234

November 1983

Final Report

Sponsored in part by:

The U.S. Consumer Product Safety Commission

Bethesda, MD 20207

100

.456

33-2791

1933 

AN ACUTE INHALATION TOXICOLOGICAL EVALUATION OF COMBUSTION PRODUCTS FROM FIRE RETARDED AND NON-FIRE RETARDED FLEXIBLE POLYURETHANE FOAM AND POLYESTER

Barbara C. Levin, Maya Paabo, Mary Lou Fultz, Cheryl Bailey, Way Yin, Steven E. Harris

U.S. DEPARTMENT OF COMMERCE

National Bureau of Standards

National Engineering Laboratory

Center for Fire Research

Washington, DC 20234

November 1983

Final Report

Sponsored in part by:

The U.S. Consumer Product Safety Commission

Bethesda, MD 20207

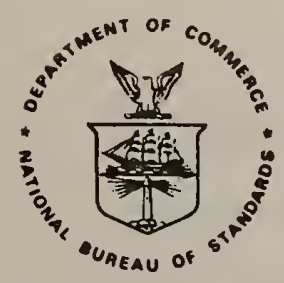

U.S. DEPARTMENT OF COMMERCE, Malcolm Baldrige, Secretary NATIONAL BUREAU OF STANDARDS, Ernest Ambler, Director 

LIST OF FIGURES. . . . . . . . . . . . . . . . . . . iv

LIST OF TABLES . . . . . . . . . . . . . . . . . . . vii

Abstract . . . . . . . . . . . . . . . . . . 1

1.0 INTRODUCTION. . . . . . . . . . . . . . . . . . . 2

2.0 MATERIALS AND METHODS . . . . . . . . . . . . . . . . 4

2.1 Materials. . . . . . . . .......... 4

2.2 Methods. . . . . . . . . . . ........ 4

2.2.1 NBS Toxicity Test Method............... 4

2.2 .2 X-ray Fluorescence. . . . . . . . . . . . . 7

2.2.3 Combustion Parameters . . . . . . . . . . . . 7

2.2.4 Two-Phase Decomposition of Polyurethane Foam. . . . . . 7

3.0 RESUlTS . . . . . . . . . . . . . . . . . . 7

3.1 X-ray Fluorescence . . . . . . . . . . . . . . 7

3.2 Rates of Heat Release and Ignition Times . . . . . . . . . 8

3.3 Autoignition Temperatures. . . . . . . . . . . . . . 8

3.4 Gas Analysis and Temperature Measurements. . . . . . . . . 8

3.4.1 Carbon Dioxide................. 8

3.4.2 Carbon Monoxide . . . . . . . . . . . 9

3.4.3 Hydrogen Cyanide. . . . . . . . . . . . 10

3.5 Toxicological Results. . . . . . . . . . . . . . 11

3.5.1 LC 50 Results. . . . . . . . . . . . . . 11

3.5.2 Post-Exposure Weight Effects. . . ....... 12

3.5.2.1 Effect of Restrainer and Head-Only

Exposure ................ 13

3.5.2.2 Correlation of Weight Loss and Amount of

Material Decomposed........... 13

3.5.2.3 Effect of Flaming or Non-Flaming

5.2 Decomposition. . . . . . . . .... 14

3.5.2.5 Weight Profiles Following Exposure to $\cdot \cdot \cdot \cdot 14$

All the Materials at One Mass Loading. . . . 15

3.5.2.6 Weight Data of Individual Animals. . . . . 16

3.5.3 10-Minute Tests . . . . . . . . . . . 16

4.0 DISCUSSION. . . . . . . . . . . . . . . . 16

5.0 CONCLUSIONS . . . . . . . . . . . . . . . . . . 20

6.0 ACKNOWLEDGEMENT . . . . . . . . . . . . . . . . . . . 22

7.0 REFERENCES. . . . . . . . . . . . . . . . . . . 22

APPENDIX . . . . . . . . . . . . . . . . . . 57 
Figure 1. Schemat1c of NBS gas analysis system. . . . . . . . . 27

Figure 2. Exposure chamber. . . . . . . . . . . . . 28

F1gure 3. Pyrolysis/combustion furnace. . . . . . . . . . 29

Figure 4. Animal restrainer . . . . . . . . . . . . 30

F1gure 5. Average 30 minute carbon monoxide concentrations (ppm) as a function of the mass loading/chamber volume (mg/l). A. - Non-flaming results. B. - Flaming results . . . . . 31

Figure 6. Rate of carbon monoxide generation (ppm) during decomposition of samples $11,12,13,14$ and 15 at mass loading/chamber volume of $30 \mathrm{mg} / \mathrm{l}$. A. - Non-flaming results. B. - Flaming results. . . . . . . . . . .

Figure 7. Hydrogen cyanide generation from polyurethane foam charred residues as a function of temperature. The residues resulted from a 30 minute experiment at the non-flaming temperature from a mass loading of $20 \mathrm{mg} / \mathrm{l}$. . .

Figure 8. Mean welght profiles of control animals normalized to the inftlal welght on day of experiment . . . . . . . 34

Flgure 9. Mean welght profiles of animals exposed to the nonflaming decomposition products of material \#11 at various mass loadings/chamber volume $(\mathrm{mg} / \ell)$. . . . . .

Figure 10. Mean welght profiles and standard deviations of animals exposed to $17.5 \mathrm{mg} / \mathrm{l}$ of material 非11 decomposed in the non-flaming mode and controls who were restrained and exposed head-only to the chamber atmosphere heated by setting the furnace at $425^{\circ} \mathrm{C}$. . . . . . . . . . . .

Figure 11. Profiles of the mean weights of animals exposed to the non-flaming thermal decomposition products of sample 112 at various mass loadings/chamber volume $(\mathrm{mg} / \mathrm{l})$. . . . . . . . . . . . . . . . .

Figure 12. Mean weight profiles of animals exposed to the non-flaming thermal decomposition products of sample $\equiv 13$ at various mass loadings/chamber volume $(\mathrm{mg} / \mathrm{l})$. . . . . . . . . . . . . . .

Figure 13. Mean weight profiles of animals exposed to the non-flaming thermal decomposition products from sample $\# 14$ at various mass loadings/chamber volume $(\mathrm{mg} / \mathrm{l})$. . . . . . . . . . . . . . . . 
Figure 14. Mean weight profiles after exposure to the nonflaming decomposition of sample $115 . . . . . . .$.

Figure 15. Additional animal mean welght profiles after exposure to the non-flaming decomposition products of matertal \#15 . . . . . . . . . . . . . . .

Figure 16. Mean weight profiles after exposure to the flaming decomposition from samples $\# 11$ and 12 at mass loadings/ chamber volume of 20,30 and $40 \mathrm{mg} / \mathrm{l}$. . . . . . . . .

Figure 17. Mean weight profiles of animals exposed to either the flaming or non-flaming decomposition products from sample $\# 13$ at mass loadings/chamber volume of 20,30 and $40 \mathrm{mg} / \mathrm{l}$.................

Figure 18. Mean weights and standard deviations of animals exposed to $40 \mathrm{mg} / \ell$ of material 1313 decomposed $1 \mathrm{n}$ the flaming and non-flaming modes ..........

Figure 19. Mean weight profiles of animals exposed to either the flaming or non-flaming decomposition products from sample 非 14 at mass loadings/chamber volume of 20 and $30 \mathrm{mg} / \mathrm{l}$. . . . . . . . . . . .

Figure 20. Profiles of mean animal weights after exposure to the flaming decomposition products of material 非15. . . . .

Figure 21. Mean weights of animals after exposure to either the flaming or non-flaming decomposition products from sample $\# 11$ at $20 \mathrm{mg} / \mathrm{l}$ (mass loading/chamber volume) . . . . . . . . . . . . . . . .

Figure 22. Mean weights of animals exposed to either the flaming or non-flaming decomposition products of sample $\# 12$ at different mass loadings/chamber volume $(\mathrm{mg} / \mathrm{l})$...................

Figure 23. Mean animal weights after exposure to the flaming and non-flaming combustion products from material \#14

Figure 24. Profiles of mean animal weights after exposure to the non-flaming thermal decomposition products from samples $\# 11$ and 12 at mass loadings/chamber volume of 20 and $30 \mathrm{mg} / \ell$............. . . . .

Figure 25. Mean weight profiles and standard deviations of animals exposed to $20 \mathrm{mg} / \ell$ of materials $\# 11$ and 12 decomposed in the non-flaming mode. . . . . . . . . 
$\underline{\text { Page }}$

F1gure 26. Profiles of mean animal welghts after exposure to the non-flaming thermal decomposition products from samples 非 13 and 14 at mass loadings/chamber volume of

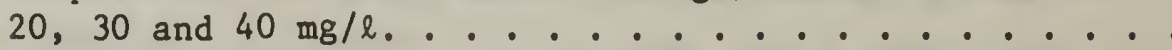

F1gure 27. Means and standard deviations of the animal welghts after exposure to $40 \mathrm{mg} / \mathrm{l}$ of mater $1 \mathrm{als}$ 非 13 and 14 decomposed in the non-flaming mode...........

F1gure 28. Profiles of mean animal welghts after exposure to the flaming decomposition of samples $\equiv_{13}$ and 14 at mass loailngs/chamber volumes of 20,30 and

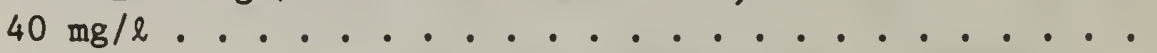

F1gure 29. Comparison of mean we1ghts of an1mals after exposure to non-flaming thermal decomposition products from samples 非1, 12, 13, 14 and 15 at a mass loading/ chamber volume of $30 \mathrm{mg} / \mathrm{l} . . . . . . . .$.

F1gure 30. Welght 1088 in individual animals exposed to nonflaming decomposition products from sample \#11 at a mass loading/chamber volume of $20 \mathrm{mg} / \mathrm{l}$. . . . . . . 


\section{LIST OF TABLES}

Page

Table 1. Ignition Times and Rate of Heat Release. . . . . . . 25

Table 2. Toxicological and Gas Results from NBS Toxicity

Test Method. . 

An Acute Inhalation Toxicological Evaluation of Combustion Products from Fire Retarded and Non-Fire Retarded Flexible Polyurethane Foam and Polyester

\author{
B. C. Levin, M. Paabo, *M.L. Fultz
}

C. Bailey, **W. Yin, S.E. Harris

\begin{abstract}
The acute inhalation toxicity of the combustion products from selected upholstered furniture filling materials with and without fire retardants was evaluated by the toxicity test method developed by the National Bureau of Standards. The fire materials that were evaluated consisted of two different formulations of flexible polyurethane foam (each formulation was supplied in both a fire retarded and non-fire retarded form) and a polyester fiberfill (not fire retarded). Atmospheric concentrations of carbon monoxide, carbon dioxide, oxygen, and hydrogen cyanide in the exposure chamber, were monitored throughout the thermal decomposition of the materials. In addition, time-to-ignition, rate of heat release, hydrogen cyanide generation via a two phase decomposition procedure and $x$-ray fluorescence measurements were performed. The LC 50 (30 minute and 14 day) values did not distinguish any of the materials as being significantly more toxic than the others. In the worst case, one of the fire retarded polyurethane foams was only a factor of two more toxic than its untreated counterpart. Only the fire retarded foams and the polyester caused deaths of the Fischer 344 rats during the 30 minute exposures. Extensive weight loss and post-exposure deaths occurred after exposure to the combustion products from all the materials. Animal deaths during or following exposure to the polyurethane cannot be attributed to carbon monoxide or hydrogen cyanide alone. Deaths during exposure to the polyester combustion products appear to be more directly related to the concentrations of carbon monoxide.
\end{abstract}

\footnotetext{
*Dr. Mary Lou Fultz, Forensic Chemist, Bureau of Alcohol, Tobacco and Firearms, 1401 Research Blvd., Rockville, MD 20850

**Mr. Way Yin, Columbia University Medical School, New York, NY 10032
} 
An Acute Inhalation Toxicological Evaluation of Combustion Products from Fire Retarded and Non-Fire

Retarded Flexible Polyurethane Foam and Polyester

\subsection{INTRODUCTION}

The largest number of U.S. fire deaths occur in one and two family residences $[1]^{1}$. The most frequent cause of residential fires is heating and cooking, while the major number of fire deaths and injuries stem from the cigarette ignition of upholstered furniture and bedding [1]. This information has led to much interest in producing fire resistant and thermally stable materials for upholstered furniture.

Most of the work in the fire retardant field has been directed toward meeting requirements in flammability regulations and voluntary standards. In 1974, however, the potential toxicological effects of combustion products from materials containing fire retardants were dramatically pointed out by the work of Petajan et al. [2]. Their study showed that the combustion products from a trimethylolpropane-based rigid urethane foam containing a reactive phosphate fire retardant caused grand mal selzures and death in rats. The presence of an obscure toxicant, 4-ethy1-1-phospha-2,6,7-trioxabicyclo [2.2.2] octane-1-oxide, was found to be responsible for the deaths in the above study. As this toxicant, under ordinary circumstances, would not have been detected by routine chemical analysis, the need for a blological test system was identifled. In addition, toxicity studies on the combustion products of materials containing fire retardants was shown to be necessary.

Herpol has reported that four fire retardant treated materials were more toxic than their untreated counterparts [3]. On the other hand, Hilado showed that the toxicity was reduced in the fire retarded materials that he tested [4]. Other studies have found that the presence of fire

\footnotetext{
${ }^{1}$ Numbers in brackets refer to the literature references listed at the end of this report.
} 
retardants do not significantly increase the toxicity or toxic combustion products (e.g., hydrogen cyanide) from materials $[5,6,7,8,9,10]$. These differing results show that the polymer formulation and the type of fire retardant will influence the toxicity of materials.

The present study was designed to assess the acute inhalation toxicity of selected upholstered furniture filling materials with and without fire retardants using the National Bureau of Standards (NBS) toxicity test method [11]. However, it should be pointed out that it is very difficult to judge the fire safety of a material by the results of only a toxicity test. The NBS toxicity test, like other small-scale laboratory tests, is conducted under specified laboratory conditions*. It was designed to assess the relative intrinsic toxicity of materials under these specified conditions and not to measure the overall toxic hazard which might occur in a real fire situation. Some of the parameters needed to evaluate the toxic hazard to which a material may contribute in a real fire situation include: the quantity of material present, its configuration, the proximity of other combustibles, the volume of the compartments to which the combustion products may spread, the ventilation conditions, the ignition and combustion properties of the material(s) present, the presence of ignition sources, the presence of fire protection systems, and the bullding occupancy.

In this study, in addition to the NBS toxicity test method data specified by the contract with the U.S. Consumer Product Safety Commission (CPSC), other fire performance criteria such as time-to-ignition, rate of heat release, hydrogen cyanide generation under the conditions of the NBS toxicity test method and via a two phase decomposition procedure were collected and evaluated. Also, $x$-ray fluorescence measurements were performed on all the materials.

* Certain commercial equipment, instruments, or materials are identified in this paper in order to adequately specify the experimental procedure. In no case does such identification imply recommendation or endorsement by the National Bureau of Standards, nor does it imply that the equipment or material identified is necessarily the best avallable for the purpose. 


\subsection{MATERIALS AND METHODS}

\subsection{Materials}

The five materials evaluated in this study were supplied by CPSC, Washington, DC 20207 and identified as FPU 非1, 12, 13, 14 and PE 非15. They consisted of two different formulations of flextble polyurethane foam (hereby specified as $A$ and $B$ ) and a polyester fiberfill. Information provided by CPSC Indicated that FPU 非1 and 12 were formulation A and FPU $\#_{13}$ and 14 were formulation B. One sample of each formulation contained a fire retardant. The polyester fiberfill was not fire retarded. Prior to testing, NBS was not informed which samples were fire retarded.

\subsection{Methods}

\subsubsection{NBS Toxicity Test Method}

The acute inhalation toxicity of the combustion products was assessed by the NBS toxicity test method [11]. Briefly, the test method consists of three major components: (1) a combustion system, (2) a chemfcal analysis system, and (3) an animal exposure system (F1g, 1). The combustion system is a closed design in which all the combustion products are generated in a furnace located directly below the 200 11ter rectangular exposure chamber (Fig. 2) and are kept within the chamber except for the volume which is transferred for chemical analysis and subsequently returned. The cup furnace is simflar to that designed by Potts and Lederer (FIg. 3) [12]. A material 1s thermally degraded at a furnace temperature $25^{\circ} \mathrm{C}$ above (flaming mode) or $25^{\circ} \mathrm{C}$ below (nonflaming mode) its predetermined autoignition temperature. In an actual flaming exposure, ethanol and/or an electric spark was used to ensure lmmediate flaming.

Before experiments, all test materials were conditioned for at least 48 hours at 40-50 percent relative humfdity and a temperature of $22-24^{\circ} \mathrm{C}$. One piece samples were tested; larger pleces were rolled and bound with wire. 
Carbon monoxide $(\mathrm{CO})$ and carbon dioxide $\left(\mathrm{CO}_{2}\right)$ were measured continuously by non-dispersive infrared spectroscopy. Oxygen $\left(\mathrm{O}_{2}\right)$ concentrations were measured continuously by a galvanic cell. The $\mathrm{CO}, \mathrm{CO}_{2}$, and $\mathrm{O}_{2}$ data were recorded by an on-line computer every 15 seconds as were the temperature measurements in the quartz beaker of the combustion system and at animal exposure positions $\mathbb{k}_{1}, 3$, and 6 . The hydrogen cyanide (HCN) generated from the polyurethane foam samples was analyzed approximately every three minutes with a gas chromatograph equipped with a thermionic detector [13].

The animals used for these experiments were Fischer 344 male rats weighing 200-300 grams. They were obtained from the Harlan SpragueDawley Company (Walkersville, MD) and were allowed to acclimate to our laboratory conditions for at least 10 days prior to experimentation. Animal care and maintenance were performed in accordance with the procedures outlined in the National Institutes of Health's "Guide for the Care and Use of Laboratory Anima1s" [14]. Each rat was housed individually in suspended stainless steel cages and provided with food and water ad libitum. Twelve hours of fluorescent lighting per day were provided using an automatic timer. All animals were weighed daily from the day of arrival until the end of the 14 day post-exposure period. Animals that were still losing weight on day 14 were weighed daily until they died or recovered as indicated by three days of successive weight gain. Control animals from the same batch were weighed daily also.

Animals designated for blood analysis of carboxyhemoglobin (COHb) underwent cannulation 24 hours before experiments. This procedure involves the surgical insertion of a cannula into the animal's femoral artery [15] thereby allowing blood samples to be taken during the exposure. The blood levels of $\mathrm{COHb}$ are indicative of the amount of carbon monoxide inhaled by the animals.

Six animals were exposed in each experiment. Each animal was placed in a restrainer (Fig. 4) which was then inserted into one of the six port- 
holes located along the front of the exposure chamber such that only the heads of the animals were exposed to the combustion atmosphere. Exposures were for 30 minutes, during which time blood was taken at 0 time, approximately 15 minutes and just before the end of the experiment from the cannulated animals (one or two animals were cannulated).

The toxicological endpoint was death. The number of animals that died at each mass loading of material was plotted to produce a concentrationresponse curve from which an $\mathrm{LC}_{50}$ (30 minutes and 14 days) was calculated. The $\mathrm{LC}_{50}$ in this case is defined as the mass loading of material per unit chamber volume $(\mathrm{mg} / \mathrm{l}$ ) which caused $50 \%$ of the animals to die during the 30 minute exposure plus the 14 day post-exposure observation period ${ }^{2}$. The $\mathrm{LC}_{50}$ 's, their 95 percent confidence limits, and the slopes of the concentration-response curves and the $95 \%$ confidence limits on the slopes were calculated via the statistical method of Litchfield and Wilcoxon [16]. According to the NBS toxicity test method, the highest concentration of material tested was $40 \mathrm{mg} / \mathrm{l}$. Therefore, in some cases the $\mathrm{LC}_{50}$ is listed as greater than $40 \mathrm{mg} / \mathrm{l}$.

If the $\mathrm{LC}_{50}$ ( $30 \mathrm{minute}$ and 14 day) values fell between $2 \mathrm{mg} / \mathrm{l}$ and $30 \mathrm{mg} / \mathrm{l}$, the animals were exposed for 10 minutes to a $30 \mathrm{mg} / \mathrm{l}$ loading. (The 10 minute test was not performed if a 30 minute test at $30 \mathrm{mg} / \mathrm{l}$ produced less than $50 \%$ death in the animals during the exposure or postexposure period even though the calculated $\mathrm{LC}_{50}$ was less than $30 \mathrm{mg} / \mathrm{l}_{\text {.) }}$ ) This 10 minute test was to determine if the material rapidly produces effective concentrations of toxic combustion products. The 10 minute exposure test was run twice at the temperature condition (flaming or non-flaming) which gave the lower $\mathrm{LC}_{50}$ value for 30 minutes and 14 days. If $50 \%$ or more of the animals from both 10 minute exposure tests died either within the 10 minutes or during a 14 day post-exposure observation period, the material was considered capable of rapidly producing toxicants.

${ }^{2}$ Animals that were still losing weight on day 14 were kept until they died or recovered as noted above. Animals that died after day 14 were included in the $\mathrm{LC}_{50}$ calculation. 


\subsubsection{X-ray F1uorescence}

$\mathrm{X}$-ray fluorescence measurements were performed to characterize all the material samples and to determine the various elements that may have been added as fire retardants. The $X$-ray energy dispersive system consisted of a tungsten tube in conjunction with titanium and molybdenum secondary emitters and a lithium-drifted silicon detector. This system detects elements with atomic numbers greater than 11 (sodium). These measurements were performed according to the procedure of Pella, et al. [17] except that the samples were analyzed as received.

\subsubsection{Combustion Parameters}

Ignition delay times and rates of heat release were determined using an oxygen consumption based technique, the NBS cone calorimeter, which has been described by Babrauskas [18]. Samples of each materia1 (非11-15) were exposed to three different radiant heat fluxes: 25,50 , and $75 \mathrm{~kW} / \mathrm{m}^{2}$. The sample size was $100 \times 100 \times 50 \mathrm{~mm}$ thick.

\subsubsection{Two Phase Decomposition of Polyurethane Foam}

A $20 \mathrm{mg} / \mathrm{l}$ sample of each polyurethane foam (非1, 12, 13 and 14) was decomposed at $25^{\circ} \mathrm{C}$ below its autoignition temperature for 30 minutes. The furnace setting was then increased so that the 30 minute residue was heated at approximately $13^{\circ} \mathrm{C}$ per minute until the final temperature was $800^{\circ} \mathrm{C}$. The time to reach $800^{\circ} \mathrm{C}$ was $32-34$ minutes. These experiments were performed to measure HCN generation under conditions previously determined by NBS to produce increased concentrations of HCN [19]. No animals were exposed in these experiments.

\subsection{RESULTS}

\subsection{X-ray F1uorescence}

The major elements detected by the energy-dispersive spectra for the five samples were bromine (sample 非1), calcium (sample 非2), phosphorus 
and chlorine (sample 非14), and antimony (sample 非5). The bromine, phosphorus and chlorine are most likely assoclated with fire retardants indicating that samples 111 and 14 were the fire retarded samples. The finding of antimony was not surprising, since it is a catalyst used in

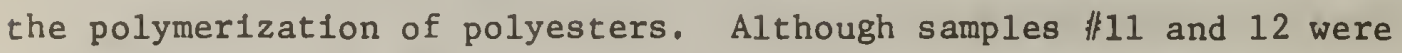
supposed to be the same formulation except for the fire retardant, the detection of a calclum compound in sample 12 was indicative of some differences.

\subsection{Rates of Heat Release and Ignition Times}

As shown in Table 1, there is no significant difference in the average heat release rate among the four polyurethane foam specimens. There is, however, some difference in 1gnition times. The two fire retarded samples (非1 and 14) take longer to ignite than the untreated ones (非12 and 13) especially at the lowest heating flux. The polyester batting (非15) did not 1 gnite at $25 \mathrm{~kW} / \mathrm{m}^{2}$ and burned at substantially lower rates at 50 and $75 \mathrm{~kW} / \mathrm{m}^{2}$ than the polyurethane foam samples.

\subsection{Auto1gnition Temperatures}

The temperature of the cup furnace which caused the samples to flame spontaneously was determined for all five materials. The aútolgnition temperature for three polyurethane samples (非11, 12 , and 13 ) was $400^{\circ} \mathrm{C}$

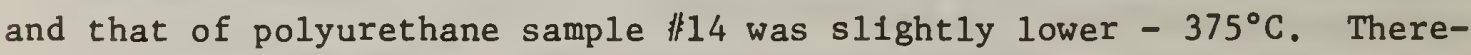
fore, the differences in materlal composition or the presence of fire retardants did not affect the autolgnition temperatures of the polyurethane foam samples. The non-fire retarded polyester materlal had a higher autolgnition temperature $\left(525^{\circ} \mathrm{C}\right)$ than the polyurethane samples.

\subsection{Gas Analys1s and Temperature Measurements}

\subsubsection{Carbon Dioxide}

Detailed analysis of the $\mathrm{CO}_{2}$ data was not attempted, since the concentration of $\mathrm{CO}_{2}$ is dependent upon both the material combustion and the animals' respiration rate and the latter changes with the amount and 
type of irritants present in the combustion atmospheres. A comparison of the $\mathrm{CO}_{2}$ values recorded in the analytical (A) and animal ( $R$ ) experiments in Table Al (appendix, sample 非1) in the non-flaming mode at a mass loading of $20.1 \mathrm{mg} / \ell$ and in the flaming mode at a mass loading of $19.8 \mathrm{mg} / \ell$ and Table A2 (sample $k_{12}$ ) in the non-flaming mode at a mass loading of $19.9 \mathrm{mg} / \ell$ (analytical-A) and $20.1 \mathrm{mg} / \ell$ (animals-R) shows the differences in $\mathrm{CO}_{2}$ between these experiments with and without animals to be 970,700 and $2060 \mathrm{ppm}$, respectively. These increased amounts of $\mathrm{CO}_{2}$ in the animal experiments are attributed to the animals' respiration.

\subsubsection{Carbon Monoxide}

The average $\mathrm{CO}$ concentrations over the 30 minute exposures at each mass loading/chamber volume are shown in Tables Al - A5 in the attached appendix. These values have been plotted in Figure 5 which shows that a linear relationship fits between the $C O$ concentrations and the mass loadings/chamber volumes for all the materials when decomposed in either the flaming mode or the non-flaming mode.

The average amount of $\mathrm{CO}$ generated from the same mass loading of each material differed as follows (Fig. 5): material 非 5 produced significantly more $\mathrm{CO}$ in both the flaming mode and the non-flaming mode than any of the other materials. The lowest average $c 0$ above $20 \mathrm{mg} / \ell$ for polyester (非15) was higher than all the data from the polyurethanes, indicating a statistically significant difference between the two types of materials [20]. Material 非1, which is fire retarded, produced more CO per mass loading in the non-flaming mode than any of the other polyurethane materials. Material 非14, however, which is also fire retarded, produced the least amount of $\mathrm{CO}$ per mass loading in the nonflaming mode. In the flaming mode, the fire retarded polyurethanes produced more $\mathrm{CO}$ than their non-fire retarded counterparts. The same statistical procedure as above [20] showed that the average amount of co generated by material 非 14 is significantly different from that of materials $\# 12$ and 13 .

The generation of $\mathrm{CO}$ over time from each of the materials at a mass loading of $30 \mathrm{mg} / \mathrm{l}$ is shown in Figure 6 . The polyester material decomposed 
In two stages, first producing $\mathrm{CO}$ at a rapid generation rate and then at a slower rate. Unlike the polyurethane materials, the polyester continued to generate $\mathrm{CO}$ for about 13 minutes in the flaming mode and throughout the 30 minute exposure in the non-flaming mode. The $\mathrm{CO}$ from the polyurethane materials leveled off in the first three minutes in the flaming mode and between 6 and 10 minutes in the non-flaming mode.

The average $\mathrm{CO}$ concentrations and carboxyhemoglobin ( $\mathrm{COHb}$ ) values calculated at the $\mathrm{LC}_{50}$ concentrations for the 30 minute exposure and 14 day post-exposure period are shown in Table 2. For the polyurethane materials, the CO levels ranged from $750 \mathrm{ppm}$ (非11, non-flaming) to 1400 ppm (非14, flaming). Carboxyhemoglobin ( $\mathrm{COHb),} \mathrm{the} \mathrm{molecule} \mathrm{which} \mathrm{forms}$ in the blood when the animals are exposed to $\mathrm{CO}$, ranged from $10-66 \%$. The polyester produced even higher $\mathrm{CO}$ and $\mathrm{COHb}$ concentrations at the $\mathrm{LC}_{50}$; the $\mathrm{CO}$ concentrations were 2650 and $3000 \mathrm{ppm}$ in the non-flaming and flaming mode, respectively; COHb levels were about $85 \%$.

\subsubsection{Hydrogen Cyanide}

The results in Table 2 show that the levels of $\mathrm{HCN}$ generated at the $\mathrm{LC}_{50}$ (30 minutes and 14 day) concentrations for each polyurethane foam in the non-flaming mode were very low, i.e., less than $10 \mathrm{ppm}$. The flaming mode produced slightly higher HCN concentrations (30-70 ppm). The highest average value (70 ppm) was observed during the decomposition of polyurethane foam 非 14 . The decomposition of $35 \mathrm{mg} / \mathrm{l}$ of polyester did not produce any HCN in either the flaming or non-flaming mode. Therefore, HCN was not routinely measured during the polyester experiments. The average HCN concentrations determined for each experiment are given in Tables A1 - A4 in the appendix.

Other studies conducted at NBS have shown that increased concentrations of $\mathrm{HCN}$ can be generated from flexible polyurethane foam if the material is decomposed in two phases (procedure is described in Section 2.2.4. Each of the polyurethane materials in this study was decomposed in this two phase manner to determine if increased $\mathrm{HCN}$ levels would be generated and the effect of the fire retardants. Heating the charred residues from the 30 minute non-flaming experiments generated increased HCN concentrations for all the polyurethane samples (Fig. 7). Polyurethane 


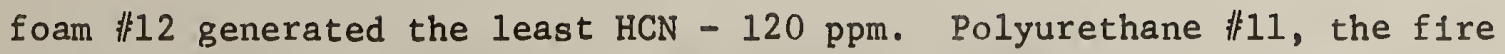
retarded counterpart to 112 , generated $210 \mathrm{ppm} \mathrm{HCN,} \mathrm{almost} \mathrm{double} \mathrm{the}$ amount for sample 非12. Non-fire retarded 非13 peaked at 180 ppm HCN, whereas its fire retarded counterpart, 非14, peaked at $220 \mathrm{ppm}$. The fire retarded materials produced more $\mathrm{HCN}$ in this two phase decomposition procedure than their non-fire retarded counterparts.

\subsection{Toxicological Results}

\section{$3.5 .1 \quad \mathrm{LC}_{50}$ Results}

The lowest $\mathrm{LC}_{50}$ values observed for the polyurethane foams were $17 \mathrm{mg} / \mathrm{l}$ for 非11 (non-flaming conditions) and $28 \mathrm{mg} / \mathrm{l}$ for 非14 (flaming conditions). All the other polyurethane $\mathrm{LC}_{50}$ values either approached or exceeded $40 \mathrm{mg} / \ell$ (Table 2). The $\mathrm{LC}_{50}$ values of the polyester fiberfill material 非15 in the flaming and non-flaming modes were 28 and $31 \mathrm{mg} / \mathrm{l}$, respectively. Based on a comparison of the $95 \%$ confidence limits, the $\mathrm{LC}_{50}$ of material \#11 is significantly different from that of materials $\|_{12} 12$ and 13 , but not that of $\#_{14}$ or 15 . However, these $\mathrm{LC}_{50}$ values were not considered toxicologically different from each other based on the classical toxicological definition which uses a factor of 10 to determine differences in degrees of toxicity [21].

The only within-exposure deaths observed during this study occurred during the flaming combustion of the fire retarded polyurethane foams, \#11 and 114 , and during the non-flaming and flaming combustion of the polyester fiberfill, 非15. The non-fire retarded foams, 非12 and 非13, caused no within-exposure deaths.

Deaths were observed during the post-exposure period after the rats were exposed to the non-flaming decomposition products from materials 非1, 12, 13 and 15 and to the flaming decomposition products from the fire retarded Dolyurethanes 非1 and 14, and from the polyester, 非15. Many of the deaths observed in the post-exposure period occurred after the animals lost a great amount of weight and after a number of days had passed. The exceptions were polyurethane foam $\# 14$ and polyester 非15 decomposed in the flaming mode. In these two cases, all post-exposure deaths occurred on the same day as the experiments. 


\subsubsection{Post-Exposure Effects}

All the animals that survived the exposures and were not cannulated to provide blood during the exposures were kept and weighed daily for at least 14 days. The weight profiles provide one indication of the postexposure health of the animals. In this study, the following questions regarding the post-exposure weights of the animals were addressed:

A. Did placing the animals in restrainers and exposing them to atmospheres heated by different furnace settings affect the control animals' weight profiles?

B. Was the weight loss experienced by the experimental animals correlated with mass loading of materlal that was thermally decomposed?

C. Which decomposition mode - flaming or non-flaming - produced the most severe effects on the post-exposure weights of the animals?

D. Did the presence of the fire retardant affect the weight profiles of the animals?

E. In a comparison of all the materials, what differences were seen in the animal weight profiles after exposure to the combustion products from a specified mass loading?

F. How does the individual animals' weight data differ from the mean weight of the surviving animals in an experiment?

Representative graphs are shown in Figures 8-30. In these graphs, the weight of the animals on the day of the experiments have been normalized to 0 to allow a visual comparison of the weight gain or loss due to the different exposure conditions. Standard deviations of the mean weights are shown in some cases to indicate the spread of the results. It should also be noted that occassional rapid increases in the mean weight may be due to the death of the animal with the lowest weight. 


\subsubsection{Effect of Restrainer and Head-On1y Exposure}

Figure 8 shows the weight profiles for four sets of control animals. In these cases, the furnace temperature was set at $425^{\circ} \mathrm{C}, 550^{\circ} \mathrm{C}, 600^{\circ} \mathrm{C}$, and $800^{\circ} \mathrm{C}$, and the animals were placed in their restrainers and exposed in the head-only mode to the atmosphere in the closed exposure chamber. No materials were burned. Although the furnace was set at the above temperatures, the average temperatures that the animals experienced ranged from $28^{\circ} \mathrm{C}$ to $47^{\circ} \mathrm{C}$ over the 30 minute exposure period. These four control groups show that the physical stress of being placed in the restrainer and being exposed to a non-toxic atmosphere could cause the animals to lose some weight during the first few days of the postexposure period. The degree of this initial welght loss did not correlate with the furnace temperature setting. In the worst case at $425^{\circ} \mathrm{C}$, the animals lost 27 grams the first day but were back to their original weight by day 5 .

\subsubsection{Correlation of Weight Loss and Amount of Material Decomposed}

Figure 9 shows the weight loss experenced by the animals following exposure to various concentrations of material 非11 which was decomposed in the non-flaming mode. The control animals shown are those (also shown in Fig. 8) which were exposed to an atmosphere where the furnace temperature was set at $425^{\circ} \mathrm{C}$. A concentration-response relationship is apparent as the animals lose more weight than the controls at the higher mass loadings $(17.5$ and $20 \mathrm{mg} / \ell$ ). At the highest mass loading, $30 \mathrm{mg} / \ell$, al1 the animals died between day 1 and day 2. Figure 10 shows the weight profiles and their standard deviations of the controls and the animals exposed to $17.5 \mathrm{mg} / \mathrm{l}$ (approximately the $\mathrm{LC}_{50}$ ) of material 非1. After day 5 , there is no overlap of the standard deviations indicating the divergence of the two curves.

A similar correlation between weight loss and concentration of combustion products was apparent from the non-flaming welght results from material \#12 (Fig. 11). This relationship between weight loss and mass loading/ chamber volume was not apparent for materials 非13 and 14 in the nonflaming mode, although in both cases, the exposed animals lost more 
weight than the untreated controls (Fig. 12 and 13). The polyester materlal 非 15 also showed a correlation between welght loss and concentration of combustion products in the non-flaming mode (F1g. 14 and 15).

In the flaming mode, the correlation between welght loss and mass loading was not evident for any of the materials. The flaming data for materials \#11 and 12 are shown in Figure 16, and that for materials 非13, 14 and 15 are in Figures 17, 19, and 20, respectively.

\subsubsection{Effect of Flaming or Nonflaming Decomposition}

Regardless of the material tested, the combustion products from the nonflaming mode produced greater effects on the weight profiles of the animals than those from the flaming mode. This is most clearly 11listrated In Figure 17 which shows the obvious difference in welght loss after the animals were exposed to elther the flaming or non-flaming combustion products from material 非3. In the non-flaming mode, the animals lost approximately 30 grams in the first two days following exposure regardless of the concentration of material decomposed. In the flaming mode, the greatest weight loss was 5.5 grams on day 2 . The mean weights and their standard deviations of the animals after exposure to $40 \mathrm{mg} / \mathrm{l}$ of material 非13 showed no overlap of the standard deviations only on day 2 when the animals exposed in the non-flaming mode lost the most welght (Fig. 18). This indicates that once the animals start to recover, there is no significant difference between the experimental and controls. Results following exposure to the other materlals are shown in Figures 19 (mater $1 a 1$ 非14), 21 (material 非1), 22 (mater1al 非12), and 23 (material 非15).

\subsubsection{Effect of the Fire Retardants}

Figure 24 compares samples 非11 and 非12 at comparable concentrations after decomposition in the non-flaming mode. Material \#11, the fire retarded material, produced a greater toxicological effect on both postexposure weights and deaths than $\#_{12}$, the corresponding untreated foam. For example, none of the animals exposed to these concentrations of material 非12 died during the post-exposure period. However, all the 
animals exposed to these concentrations from material 非1 did die during the post-exposure perfod. The higher the concentration, the sooner the deaths occurred. Comparison of mean welghts and standard deviations of anlmals exposed to $20 \mathrm{mg} / \ell$ of materials 非1 and 12 decomposed in the non-flaming mode showed no overlap of the standard deviations between material 非1 and the control data (Fig. 25). Material 非2 did overlap with the control.

Although the $\mathrm{LC}_{50}$ values in Table 2 were the same, the weight profiles of the animals after exposure to samples $⿰ ⿰ 三 丨 ⿰ 丨 三 11$ and $\# 12$ in the flaming mode indicate that exposure to material 非1 was generally more severe than exposure to $\#_{12}$ (Fig. 16). The differences are not as obvious as in the non-flaming mode.

Figure 26 compares the non-flaming results for materials 非3 (non-fire retarded) and $\#_{14}$ (fire retarded). Both materials show the same initial weight 1oss. The animals exposed to material 非 13 show an attempt to recover about days 5 and 6 and then again lose weight, after which some recovery is seen. The higher concentrations of material 非14 appear to cause the animals to recover more slowly than seen with material 非3; however, this may be an artifact due to no data at the time the recovery would have occurred. These results at the highest mass loading/chamber volume tested $(40 \mathrm{mg} / \mathrm{l})$ were plotted along with their standard deviations (Fig. 27). The control data is incomplete between days $4-6$ but the remaining results indicate that no overlap of the standard deviations occurs on days 2 and 3 following the exposure and that by day 7 , there is no difference between the exposed and control animals. The flaming results from materials $\$ 13$ and 1314 did not show any significant differences (Fig. 28).

\subsubsection{Weight Profiles Following Exposure to All the Materials at One Mass Loading}

Figure 29 compares the non-flaming results for materials $⿰ ⿰ 三 丨 ⿰ 丨 三 11,12,13$, 14 , and 15 at $30 \mathrm{mg} / \mathrm{l}$. The decomposition products from 非1 caused all the animals to die on day 1 . The other materials all caused about the same initial weight loss for the first two days, after which a period of 
recovery is noted (except 非14) for three days. The animals then either continue to recover (非15) or experienced additional weight losses before starting to gain welght. The only material other than 1 ll to cause deaths in these 111 ustrated experiments was $\#_{13}$ which caused one death on day 11 .

\subsubsection{Weight Data of Individual Animals}

In each experiment, six animals were exposed to the combustion products and all surviving animals, which were not sacrificed for blood, were welghed dally. In all the above cases, the mean welghts of the remaining animals were calculated and plotted. However, since individual animals died at various times, Figure 30 illustrates each individual animal's welght loss and day of death after exposure to $20 \mathrm{mg} / \ell$ of material 非1. All the animals reacted in a similar way, 1.e., they initially lost welght for two days, appeared to recover through day 6 or 7 , and then started losing welght again until they died. In this experiment, the greatest weight loss was 91 grams.

\subsubsection{0-Minute Tests}

Ten minute tests were performed for polyurethane mode where the $\mathrm{LC}_{50}$ was $17 \mathrm{mg} / \mathrm{l}$, and for polyurethane 1314 in the flaming mode where the $\mathrm{LC}_{50}$ was $28 \mathrm{mg} / \mathrm{l}$. In both cases, no animals died either during the exposure or during the 14 day post-exposure period. The $\mathrm{LC}_{50}$ for the polyester fiberfill in the non-flaming mode was $28 \mathrm{mg} / \mathrm{l}$, but since 30 minute experiments had been carried out with this material at $30 \mathrm{mg} / \ell$ and $32 \mathrm{mg} / \ell$ and 1 ess than $50 \%$ of the animals had died efther within or post-exposure, it was concluded that a 10 minute exposure to $30 \mathrm{mg} / \ell$ would also not produce $50 \%$ deaths.

\subsection{DISCUSSION}

The purpose of this study was to compare upholstered furniture f11ling materials, in particular two different formulations of flexible polyurethane foam and a polyester flberfill. Each formulation of polyurethane 
foam was supplied as two samples, one of which contained a fire retardant. Therefore, a total of five samples were evaluated. These samples were coded as polyurethane $k_{11}, 12,13$, and 14 and polyester $\equiv_{15}$.

The time-to-ignition was examined under three heat fluxes, 25, 50, and $75 \mathrm{~kW} / \mathrm{m}^{2}$, and the results indicated that the two fire retarded polyurethane foam specimens ( $\$ 111$ and 14) take longer to ignite than the untreated ones (非12 and 13), expecially at the lowest heating flux. This also suggests that over a certain range of heating fluxes, the flame spread might be slower over the fire retarded samples than over the untreated samples. This advantage would diminish at higher fluxes. At the lowest heat flux tested, the polyester fiberfill did not ignite and the times-to-ignition were longer at the higher heat fluxes than those noted for any of the polyurethane foams.

The rate of heat release data showed no significant differences among the four polyurethane samples. In other words, once ignited, the burning rates of these samples are almost identical. The polyester fiberfill's rate of heat release was lower than any of the polyurethane samples at any given heat flux. However, it should be noted that the actual packing density of a fiberfill can vary widely and the density of the polyester packing would affect the heat release rate. Nonetheless, it is clear that, in comparison to these polyurethane samples, this polyester is less ignitable and has a lower heat release rate.

The autoignition temperatures which were determined as part of the NBS toxicity test method $\left(400^{\circ} \mathrm{C}\right.$ for polyurethane foams $k_{111,12}$ and $13,375^{\circ} \mathrm{C}$ for polyurethane foam 114 and $525^{\circ} \mathrm{C}$ for the polyester) indicated that the autoignition temperatures were not affected by the presence of the flame retardants. This value is determined under different conditions than the ignition time. The autoignition temperature is found by placing the sample in a quartz cup which has been preheated to different temperatures and determining the temperature which causes the material to flame. The ignition time is determined by exposing a sample to different heat fluxes and measuring the time at which it ignites. Since the autoignition temperatures were similar and little difference was observed in times-to-ignition at high heat fluxes, the cup furnace exposure appears comparable to the higher heat fluxes used in the ignition time tests. 
The polyester fiberfill, which was the least ignitable at the high heat flux exposures, had the highest autoignition temperature.

Pure gas studies performed at NBS have shown that the $\mathrm{LC}_{50}$ for a 30 minute CO exposure is $5000 \mathrm{ppm}$ (when the animals are exposed gradually, i.e., the $\mathrm{CO}$ is introduced into the exposure chamber over a 5 minute period) or $4600 \mathrm{ppm}$ (when the animals are exposed immediately). Carboxyhemoglobin, the molecule that forms in the blood when the animals are exposed to CO, will reach $87-89 \%$ before the animals die. For these polyurethanes, the $C O$ concentrations at the $\mathrm{LC}_{50}$ ranged from $750 \mathrm{ppm}$ to $1400 \mathrm{ppm}$ and for this polyester, the CO concentrations were $2650 \mathrm{ppm}$ and $3000 \mathrm{ppm}$ at the $\mathrm{LC}_{50}$ 's in the non-flaming and flaming modes, respectively. The highest $\mathrm{COHb}$ levels noted in this study ranged from $10 \%$ to $66 \%$ for the polyurethane materials and about $85 \%$ for the polyester. These results indicate that the $\mathrm{CO}$ and $\mathrm{COHb}$ levels generated at the $\mathrm{LC}_{50}$ ( 30 minutes and 14 day) concentrations of the polyurethane foam were not sufficient to account for the deaths of the animals. Although the CO levels generated at the $\mathrm{LC}_{50}$ value for the polyester were lower than the lethal levels seen in the pure gas studies, the $\mathrm{COHb}$ levels were high enough (85\%) to consider $\mathrm{CO}$ as the primary toxicant.

Another factor to consider is that most of the deaths observed in this study occurred post-exposure. (Exceptions were polyurethane $\equiv_{1} 14$ in the flaming mode in which half the animals died the same day of the experiment and polyester $\equiv_{15}$ in which most of the deaths occurred during the exposure.) The NBS pure CO studies have shown that if the animals survive the exposure, they will not succumb during the post-exposure period. Therefore, the post-exposure deaths should not be attributed to $\mathrm{CO}$.

$\mathrm{HCN}$ can be generated during the thermal decomposition of any nitrogencontaining polymer. Therefore, HCN concentrations were measured during the decomposition of the polyurethane samples, but not the polyester material. Pure gas studies at NBS have indicated that approximately $160 \mathrm{ppm}$ of $\mathrm{HCN}$ for 30 minutes are necessary to kill $50 \%$ of the animals during exposure to the NBS toxicity test method conditions. Examination of the HCN results presented in Table 2 shows that the HCN levels ranged from less than $10 \mathrm{ppm}$ to $70 \mathrm{ppm}$ and therefore were never high enough to 
account for the within-exposure deaths. Although $\mathrm{CO}$ and $\mathrm{HCN}$ are probably contributing to the within-exposure deaths of the animals exposed to polyurethane combustion products, there appear to be additional factors or toxic gases which are not yet understood. Also the reasons for the post-exposure deaths are st111 unclear.

This study also has shown that increased amounts of $\mathrm{HCN}$ can be generated from the polyurethane samples if they are decomposed according to a two phase procedure developed at NBS. This two phase decomposition procedure simulates a real fire scenario, namely, that of a polyurethane upholstered chair which smolders for some unspecified time forming a char and eventually 1gnites. These results indicated that the fire retarded samples produced more $\mathrm{HCN}$ than the untreated specimens. Although no animals were exposed in this series of experiments, it is clear that the $\mathrm{LC}_{50}$ (30 min) levels of pure $\mathrm{HCN}$ were reached in the case of materiais $\#_{11}, 13$, and 14.

The materials examined in this study should not be rank ordered based on the calculated $\mathrm{LC}_{50}$ values. Toxicologically, the $\mathrm{LC}_{50}$ 's should differ by a factor of 10 before any one is considered significantly more toxic than another [21]. In this study, the $\mathrm{LC}_{50}$ 's were not found to be toxicologically different. However, it is interesting to note that the non-fire retarded polyurethane foams (非12 and 13) produced only postexposure deaths and those only in the non-flaming mode. The fire retarded foams (非1 and 14) produced within-exposure deaths but only in the flaming mode. The post-exposure deaths that resulted from the fire retarded foams were in the non-flaming mode (非11) and flaming mode (非11 and 14). The production of within-exposure deaths from the fire retarded foams only is indicative of a rapidly acting toxicant (within 30 minutes) being generated by the flaming combustion.

The 10 minute tests designed to determine whether these materials rapidly produced effective concentrations of toxicants were performed for the two materials not previously tested for 30 minutes at $30 \mathrm{mg} / \mathrm{l}$. These materials did not rapidly produce (within 10 minutes) lethal levels of toxicants at those concentrations.

The weight profiles of the animals after exposure to the combustion products of the materials were also evaluated in this study. The greater 


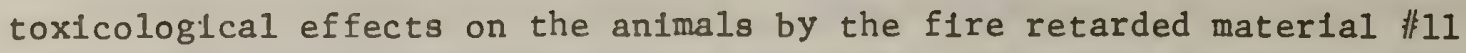
was reflected by increased welght $10 s$ and less rapid recovery than seen with material 非12 which was untreated. The combustion products from materials $\equiv_{1} 13$ and 非14 appeared to have about equal effects on the postexposure welghts of the animals.

In addition, the welght profiles indicated that the non-flaming conditions caused greater post-exposure effects than the flaming conditions. After exposure to the non-flaming conditions, the animals lost weight in the first few days, appeared to stabllize or recover slightly and then, about day 5-7, began to lose welght again. Material 非5, the polyester, did not produce the second weight loss. It was during this second period of welght loss that most of the deaths from the polyurethanes occurred. The deaths that did occur during the first few days are probably directly related to the insult caused by the toxic exposure. Some of the control data indicates that, in some cases, the inftial weight loss may be due to the physical stress of being restrained and not the chemical stress of the toxicants. The welght loss and deaths that occur later, however, are most likely related to the toxic insult which caused physiological damage or increased susceptibility to secondary infection.

\subsection{CONCLUSIONS}

As a result of this study, the following conclusions can be stated:

- The $\mathrm{LC}_{50}$ (30 minute and 14 day) values did not distinguish any of the test materials as being toxicologically different from the the others. The worst case fire retarded material 非11 was only a factor of two more toxic than 1 ts untreated counterpart.

- The fire retarded polyurethane foam decomposition products caused within-exposure deaths. No such deaths were observed when the non-fire retarded polyurethane samples were burned.

- Exposure to the combustion products of these materials caused extensive weight loss of the animals during the post-exposure 
period and, in many cases, death. The non-flaming mode produced greater welght losses than the flaming mode. The effect of stress on the animal welghts during the early post-exposure perlod cannot be clearly separated from the effect of the toxicants.

- The physiological explanation for the late-occurring post-exposure deaths is not known.

- The animal deaths from exposure to the combustion products from the polyurethane foams tested cannot be attributed to $\mathrm{CO}$ or $\mathrm{HCN}$ alone.

- Animal deaths due to the combustion products of the polyester were generally within-exposure and appear to be more directly related to the $\mathrm{CO}$ concentrations.

- The greatest concentration of $\mathrm{CO}$ was generated by the polyester regardless of the combustion mode (flaming or non-flaming). The fire retarded polyurethanes generated more $\mathrm{CO}$ in the flaming mode than the non-fire retarded polyurethanes. This difference was not observed in the non-flaming mode.

- Increased concentrations of $\mathrm{HCN}$ can be generated from the polyurethane foams by a two phase decomposition procedure. The fire retarded materials produced even more $\mathrm{HCN}$ than the untreated samples.

- The rate of heat release for the polyurethane materials increased with increased heat flux and was comparable for all the foams at a given heat flux. The polyester burned at lower rates when compared to the polyurethane foams at a given heat flux.

- The autoignition temperatures of the polyurethane foams 非11 (fire retarded), 12 , and 13 were the same. Number 14 (fire retarded) was $25^{\circ} \mathrm{C}$ lower than the other polyurethane foams. Therefore, fire 
retardants did not affect the temperature at which the samples flamed. The polyester was $125^{\circ} \mathrm{C}$ higher indlcating lower ignitability.

- The fire retarded polyurethane samples had longer times-to-1gnition than the untreated samples at the lowest heat flux tested. At higher heat fluxes, the times were comparable. The polyester had the longest time-to-ignition at all heat fluxes tested.

\subsection{ACKNOWLEDGEMENT}

The authors gratefully acknowledge the help of the Materials Fire Properties Group, Center for Fire Research, Dr. V. Babrauskas, Head, who performed and interpreted the rate of heat release and time-to-1gnition experiments. We also thank Mr. E. Braun, who wrote the computer program for storing and graphing the post-exposure animal welghts and Ms. M. Diephaus and Ms. A. Durham who skillfully used these computer programs to prepare many of the figures. The statistical guidance of Dr. Hsien H. Ku, Statistical Englneering Division, Center for Applied Mathematics, NBS, is also appreclated greatly. Dr. M.L. Fultz, Mr. S.E. Harris and Mr. W. Yin were guest workers from the University of Pittsburgh. Our appreciation is also expressed to Mrs. E. Granger for her timely and expert typing of this manuscript.

This experimental work was performed under Contract CPSC-IAG-74-75, Task Order 82-1 from the U.S. Consumer Product Safety Commission, Dr. Rita Orzel, Project Representative. The opinfons expressed hereln are those of the authors and not those of CPSC.

\subsection{REFERENCES}

1. Federal Emergency Management Agency, Fire in the United States, 2nd Edition, FEMA-22, July 1982.

2. Petajan, J.H., Voorhees, K.J., Packham, S.C., Baldwin, R.C., Einhorn, I.N., Grunnet, M.L., Dinger, B.G., and Birky, M.M., Extreme toxicity from combustion products of a fire-retarded polyurethane foam. Sclence 187: 742-744 (1974). 
3. Herpo1, C., Toxicity of products of pyrolysis and combustion of the fire retardant and untreated woods and synthetic polymers. In "Fire Retardants: Proceedings of 1st European Conference on Flammability and Fire Retardants," Ed. by V.M. Bhatnagar, Technomic Publishing Co. Inc., Westport, CT. p. 64-74 (1977).

4. Hilado, C.J., Relative toxicity of pyrolysis products of some foams and fabrics. J. Comb. Tox. 3: 32-60 (1976).

5. Wei1, E.D., and Aaronson, A.M., Phosphorus flame retardants meeting new requirements, In "Fire Retardants: Proceedings of 1st European Conference on Flammability and Fire Retardants," Ed. by V.M. Bhatnager. Technomic Publishing Co. Inc., Westport, CT. p. 163-180 (1977).

6. Ashida, K., Yamauchi, F., Katoh, M., and Harada, T., HCN generation from urethane and isocyanurate foams. J. Cell. Plastics, 10: 181-185 (1975).

7. Benisek, L., The effect of the Zirpro flame-resistant treatments on flame retardance, smoke emission and toxicity of combustion products (NBS Developmental Test), J. Comb. Tox. $\underline{8}$ : 233-241 (1981).

8. Alarie, Y.C., Wilson, E., Civic, T., Magill, J.J., Funt, J.M., Barrow, C., and Frohliger, J., Sensory irritation evoked by polyurethane decomposition products. JFF/Comb. Tox. 2: 139-150 (1975).

9. Hilado, C.J. and Furst, A., Relative toxicity of pyrolysis products of some materials used in home furnishings. J. Comb. Tox. $\underline{3}$ : 425-464 (1976).

10. Keller, J.G., Herrera, W.R., Johnston, B.E., An investigation of potential inhalation toxicity of smoke from rigid polyurethane foams and polyester fabrics containing antiblaze 19 flame retardant additive. J. Comb. Tox. 3 : 296-304 (1976).

11. Levin, B.C., Fowe11, A.J., Birky, M.M., Paabo, M., Stolte, A., and Malek, D., Further development of a test method for the assess ment of the acute inhalation toxicity of combustion products. Nat. Bur. Stand. (U.S.) NBSIR 82-2532, June 1982, 143 p.

12. Potts, W.J., and Lederer, T.S., A method for comparative testing of smoke toxicity. J. Comb. Tox 4: 114-162 (1977).

13. Paabo, M., Birky, M.M., and Womble, S.E., Analysis of hydrogen cyanide in fire environments. J. Comb. Tox. 6: 99-108 (1979).

14. Committee on Care and Use of Laboratory Animals, Guide for the care and use of laboratory animals. DHEW publication No. (NIH) 78-23. U.S. Dept. of HEW, Public Health Service, National Institutes of Health (1978). 
15. Packham, S.C., Frens, D.B., McCandless, J.B., Patajan, J.H., and Birky, M.M., A chronic intra-arterial cannula and rapid technique for carboxyhemoglobin determination. J. Comb. Tox. 3 : 471-478 (1976).

16. Litchfield, J.T., Jr., and Wilcoxon, F., A simplified method of evaluating dose-effect experiments. J. Pharmacol. and Exp. Therapeut. 96: 99-113 (1949).

17. Pella, P.A., Lorber, K.E., and Heinrich, K.F.J., Energy-dispersive $\mathrm{X}$-ray spectrometric analysis of environmental samples after borate fusion. Anal. Chem. 50: 1268-1271 (1978).

18. Babrauskas, V., Development of the cone calorimeter - a bench-scale heat release rate apparatus based on oxygen consumption. Nat. Bur. Stand. (U.S.), NBSIR 82-2611, Nov. 1982, 84 p.

19. NBS results, to be published.

20. Tukey, J.W., A quick compact, two-sample test to Duckworth's specifications. Technometrics 1:31-48 (1959).

21. Klaassen, C.D. and Dou11, J., Evaluation of safety: toxicological evaluation, In "Casarett and Doull's Toxicology" Ed. by Doull, J., Klaassen, C.D. and Amdur, M.O. 2nd Edition, Chapter 2, p. 12. Macmillan Pub1. Co., Inc. New York, Toronto, and London. 1980. 
Table 1

Ignition Times and Rate of Heat Release

\begin{tabular}{|c|c|c|c|c|}
\hline Material & $\begin{array}{l}\text { Heating } \\
\text { F1ux } \\
\left(\mathrm{kW} / \mathrm{m}^{2}\right)\end{array}$ & $\begin{array}{l}\text { Ignition } \\
\text { Time } \\
\text { (sec) }\end{array}$ & $\begin{array}{l}\text { Peak Heat } \\
\text { Releage } \\
\left(\mathrm{kW} / \mathrm{m}^{2}\right)\end{array}$ & $\begin{array}{c}60 \mathrm{sec} \text {. Average } \\
\text { Heat Release } \\
\left(\mathrm{kW} / \mathrm{m}^{2}\right)\end{array}$ \\
\hline 11 & $\begin{array}{l}25 \\
50 \\
75\end{array}$ & $\begin{array}{r}39.2 \\
4.1 \\
2.7\end{array}$ & $\begin{array}{r}438 \\
1029 \\
1429\end{array}$ & $\begin{array}{l}276 \\
456 \\
545\end{array}$ \\
\hline 12 & $\begin{array}{l}25 \\
50 \\
75\end{array}$ & $\begin{array}{l}5.5 \\
3.3 \\
1.3\end{array}$ & $\begin{array}{r}433 \\
1059 \\
1773\end{array}$ & $\begin{array}{l}278 \\
443 \\
501\end{array}$ \\
\hline 13 & $\begin{array}{l}25 \\
50 \\
75\end{array}$ & $\begin{array}{l}5.2 \\
3.3 \\
\text { NA }\end{array}$ & $\begin{array}{r}466 \\
876 \\
1810\end{array}$ & $\begin{array}{l}272 \\
470 \\
646\end{array}$ \\
\hline 14 & $\begin{array}{l}25 \\
50 \\
75\end{array}$ & $\begin{array}{r}15.0 \\
4.1 \\
2.9\end{array}$ & $\begin{array}{r}467 \\
844 \\
1862\end{array}$ & $\begin{array}{l}230 \\
428 \\
561\end{array}$ \\
\hline 15 & $\begin{array}{l}25 \\
50 \\
75\end{array}$ & $\begin{array}{r}\infty \\
10.2 \\
9.2\end{array}$ & $\begin{array}{r}0 \\
247 \\
259\end{array}$ & $\begin{array}{r}0 \\
149 \\
129\end{array}$ \\
\hline
\end{tabular}




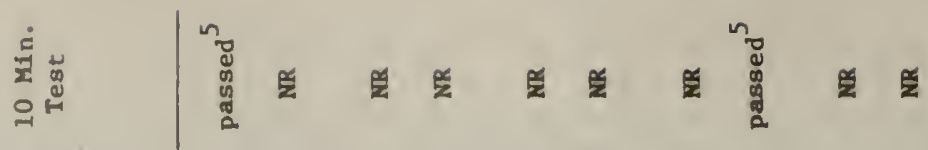
岁岁号

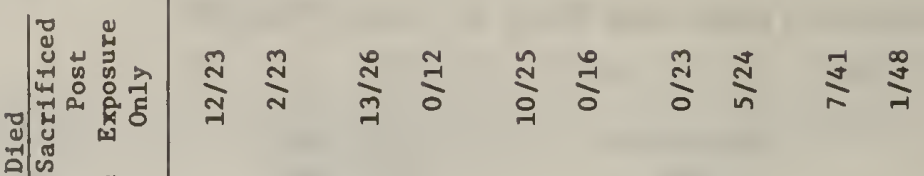

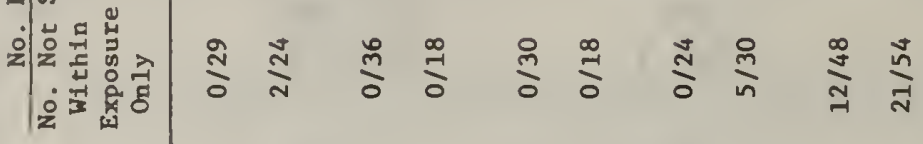

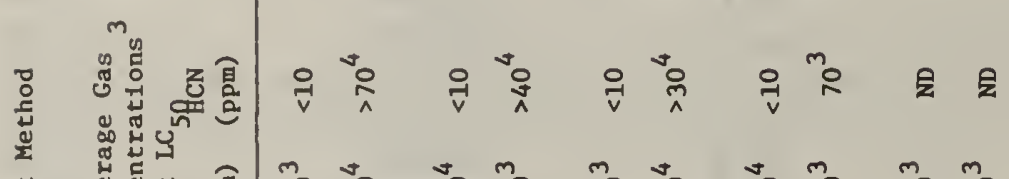

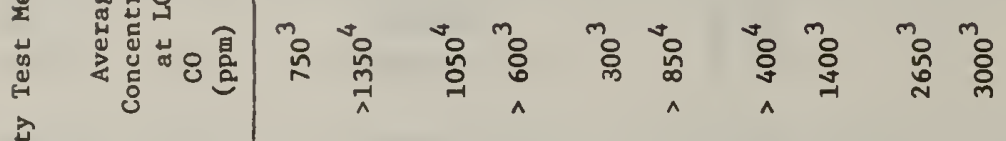

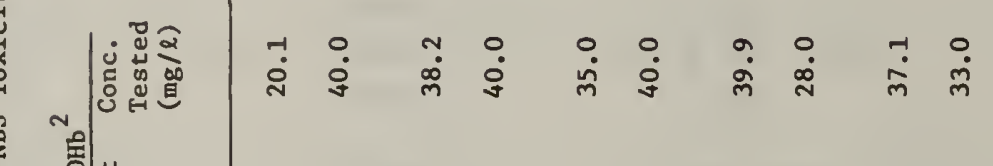

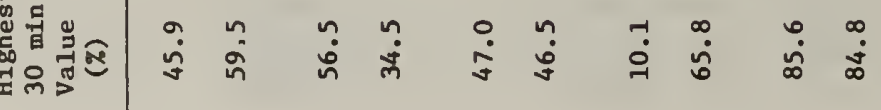

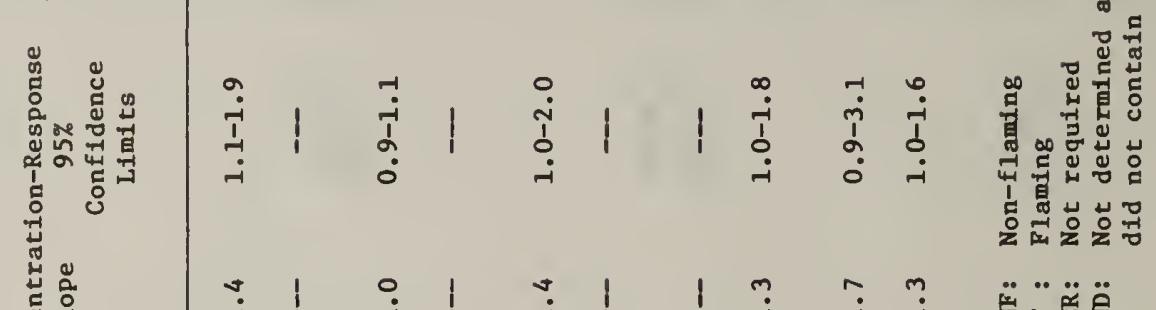

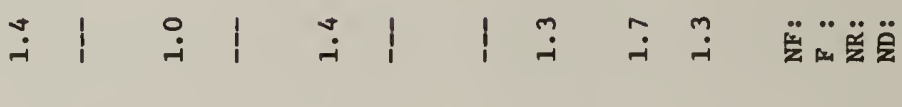

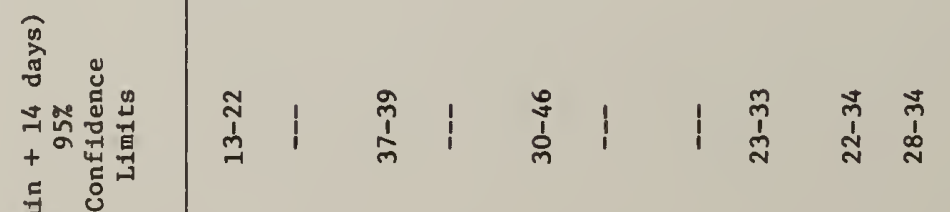

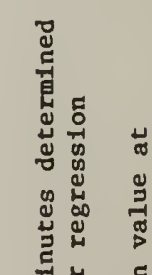

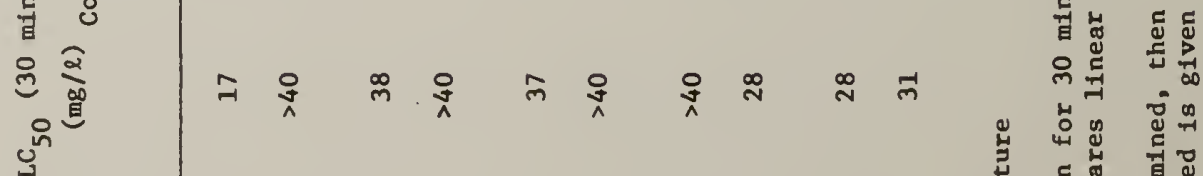

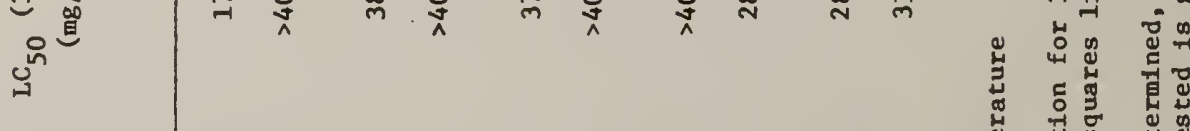

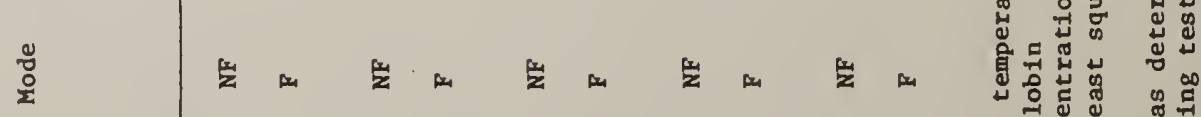

苞造 \& \& 8 \&

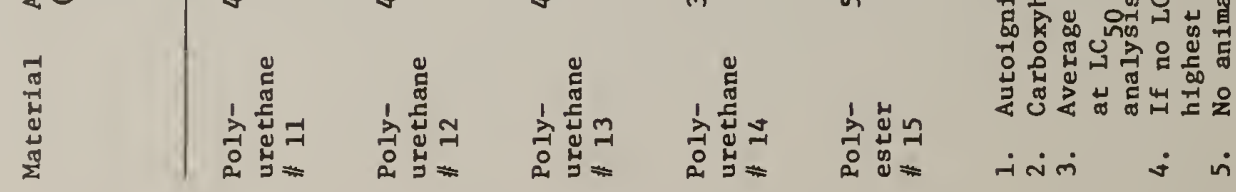




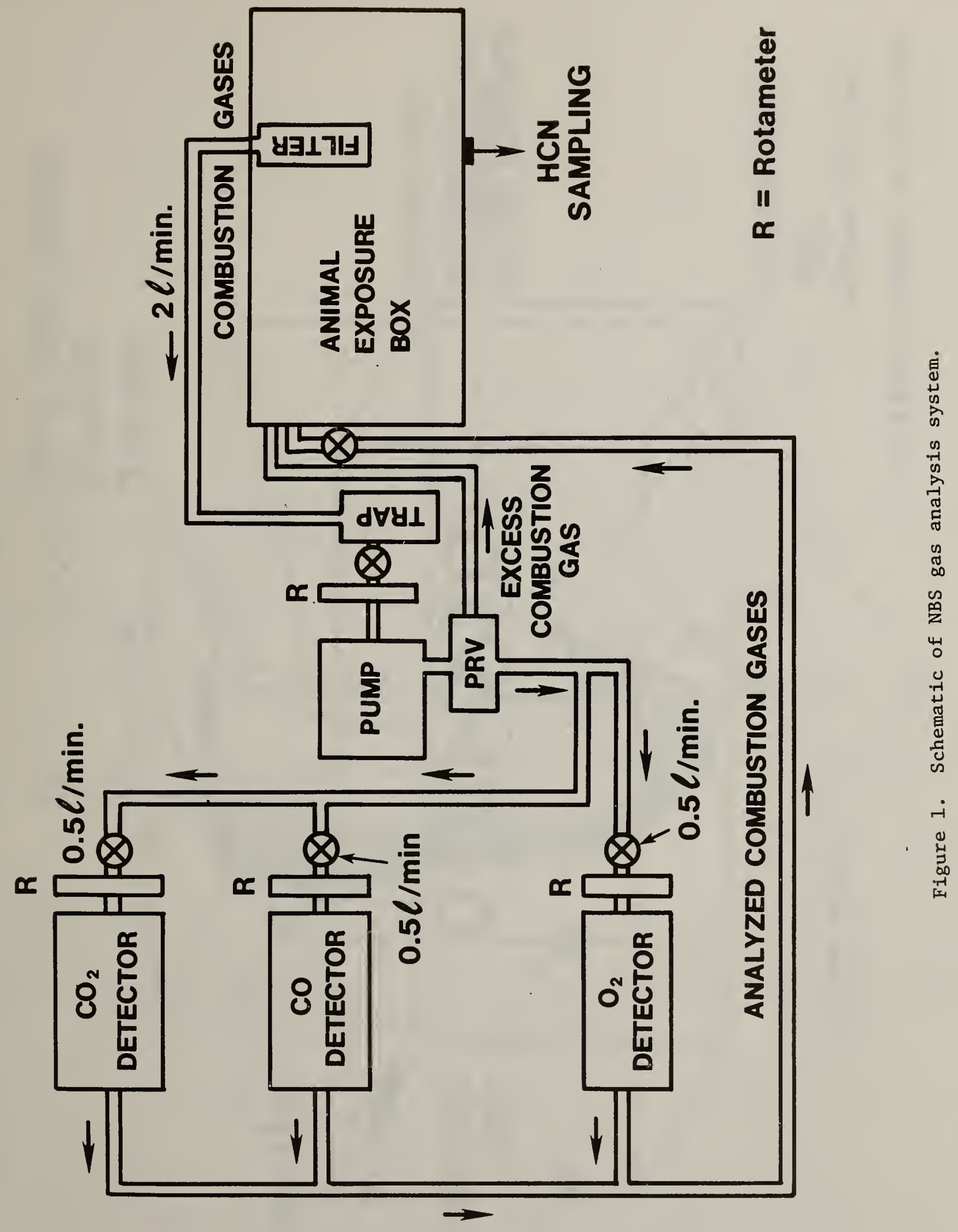




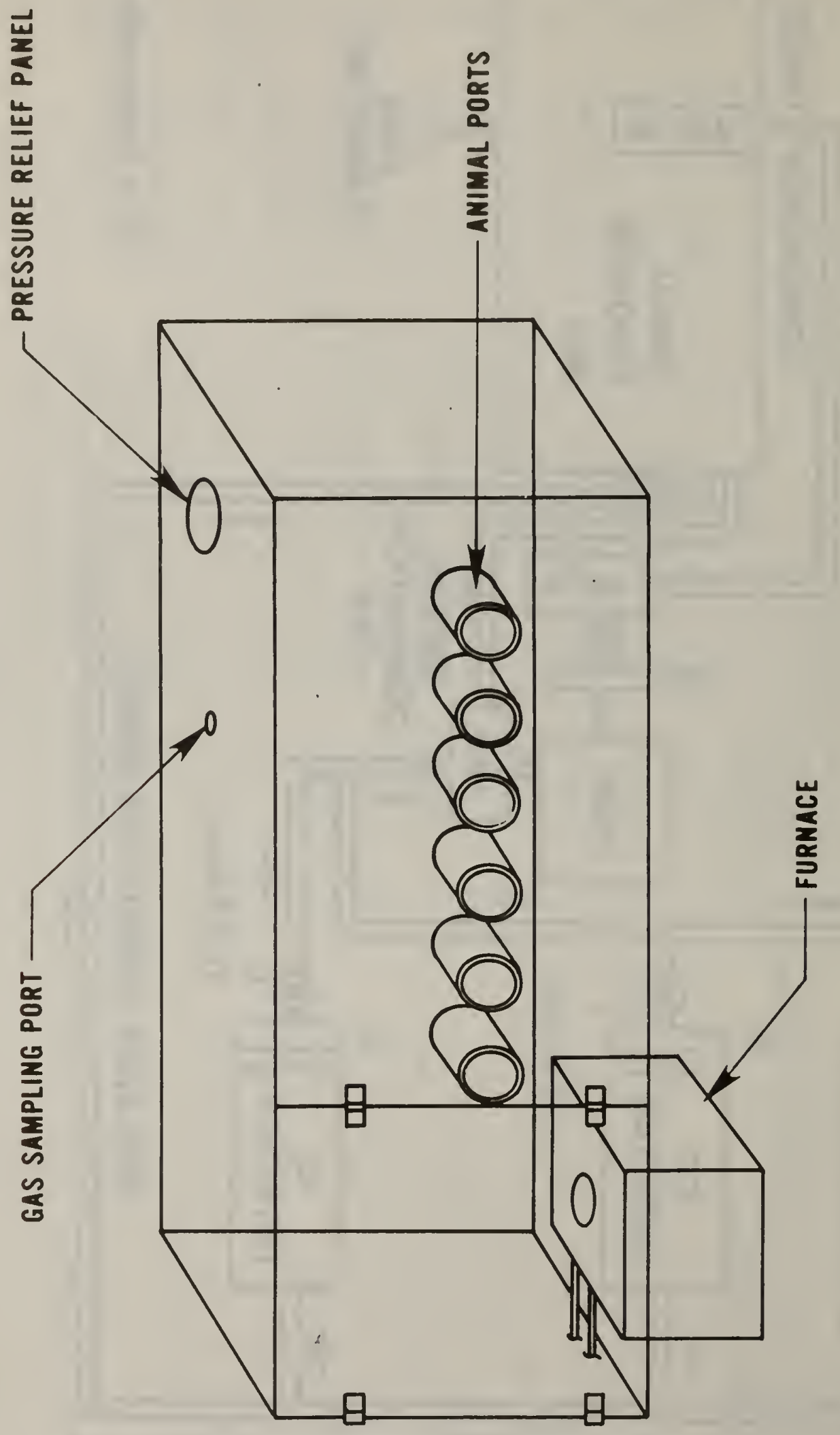

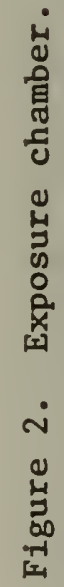




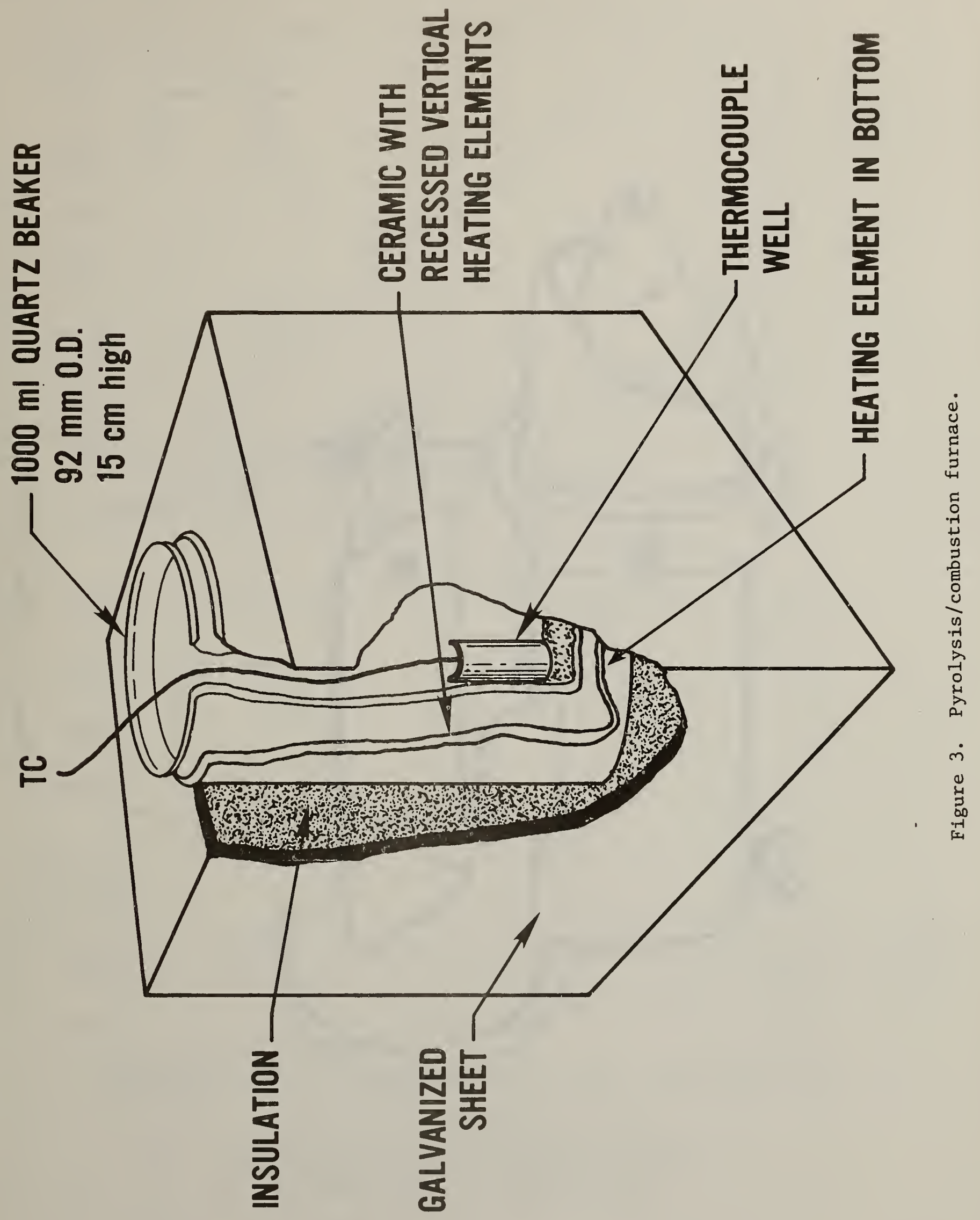




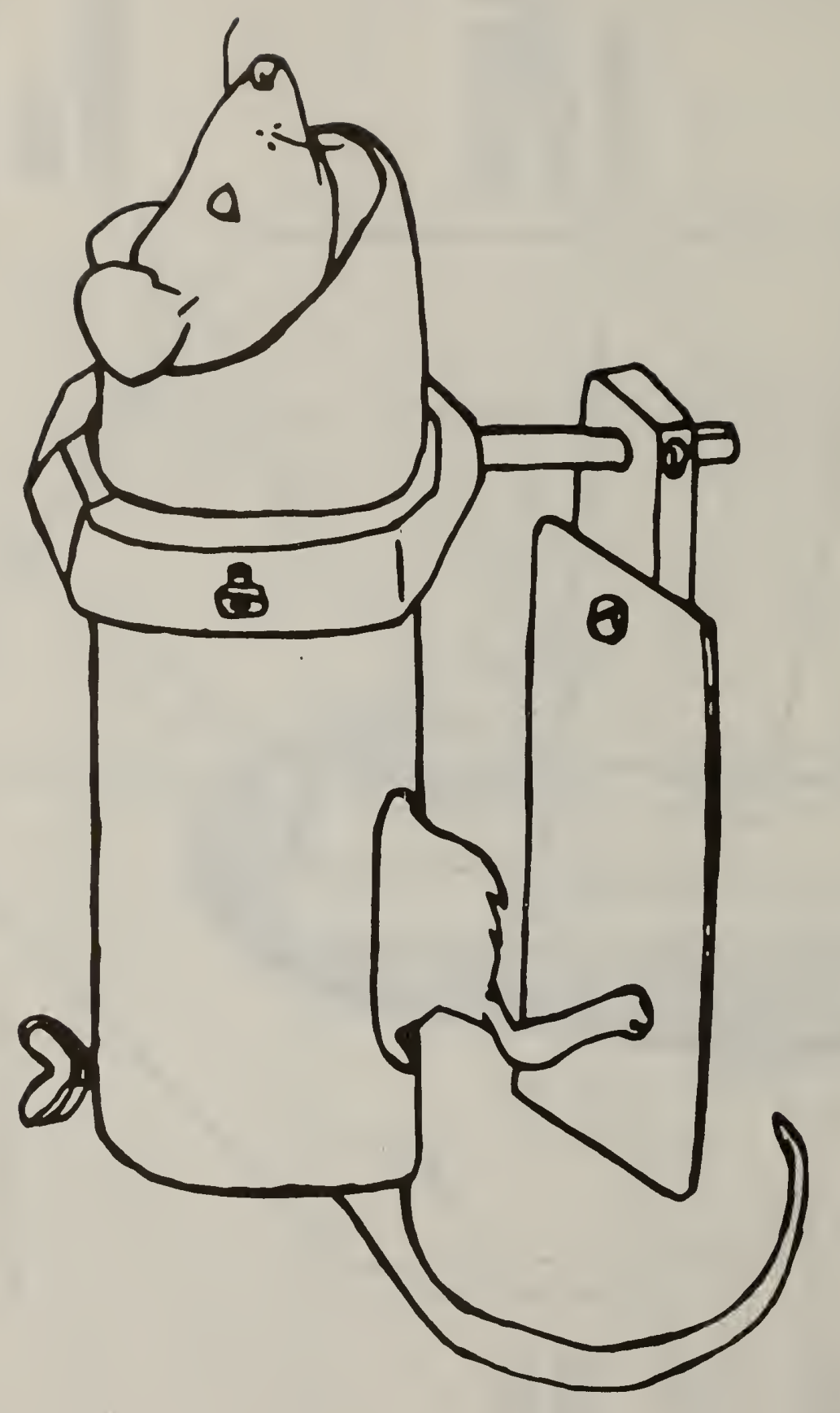

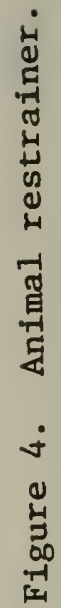



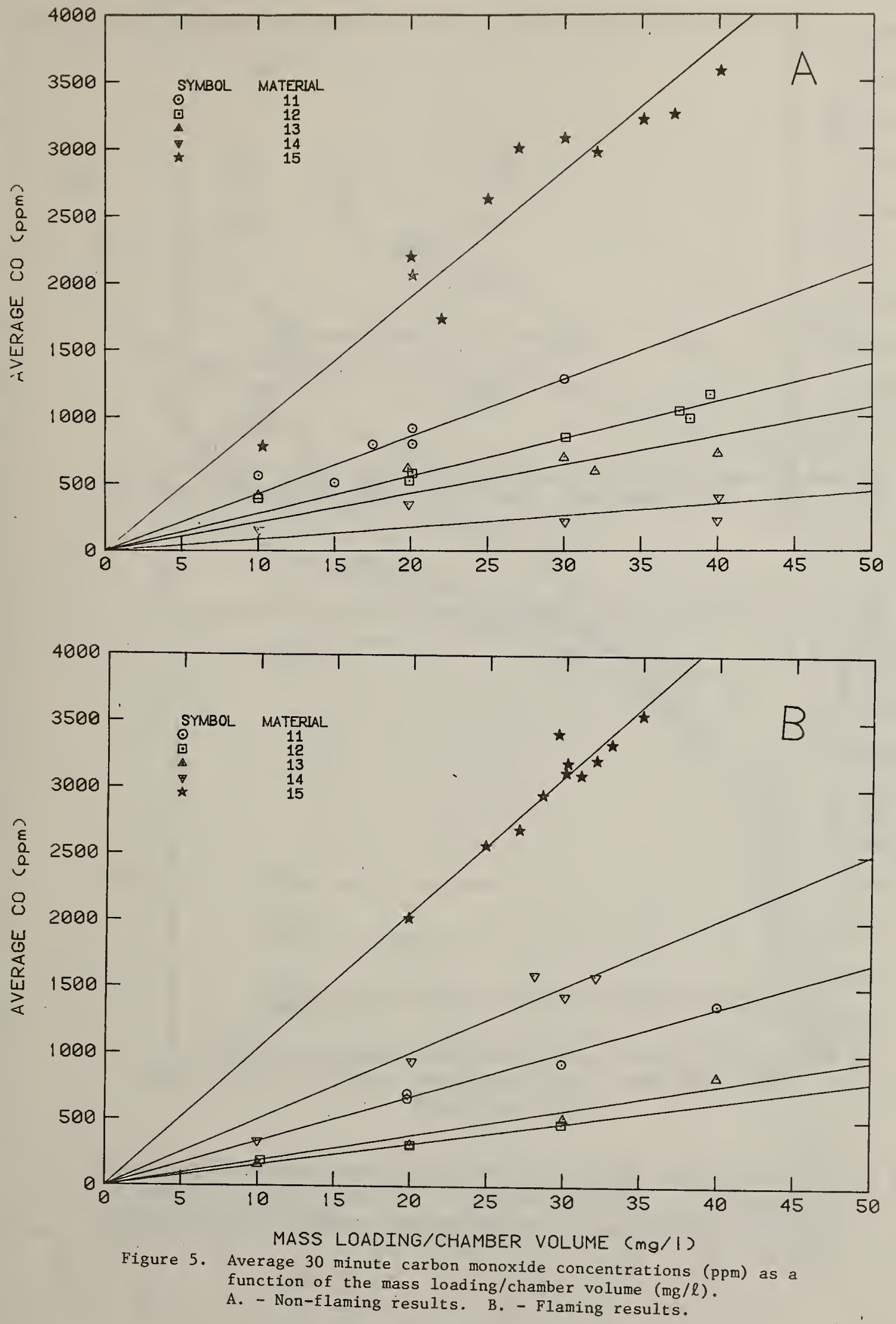

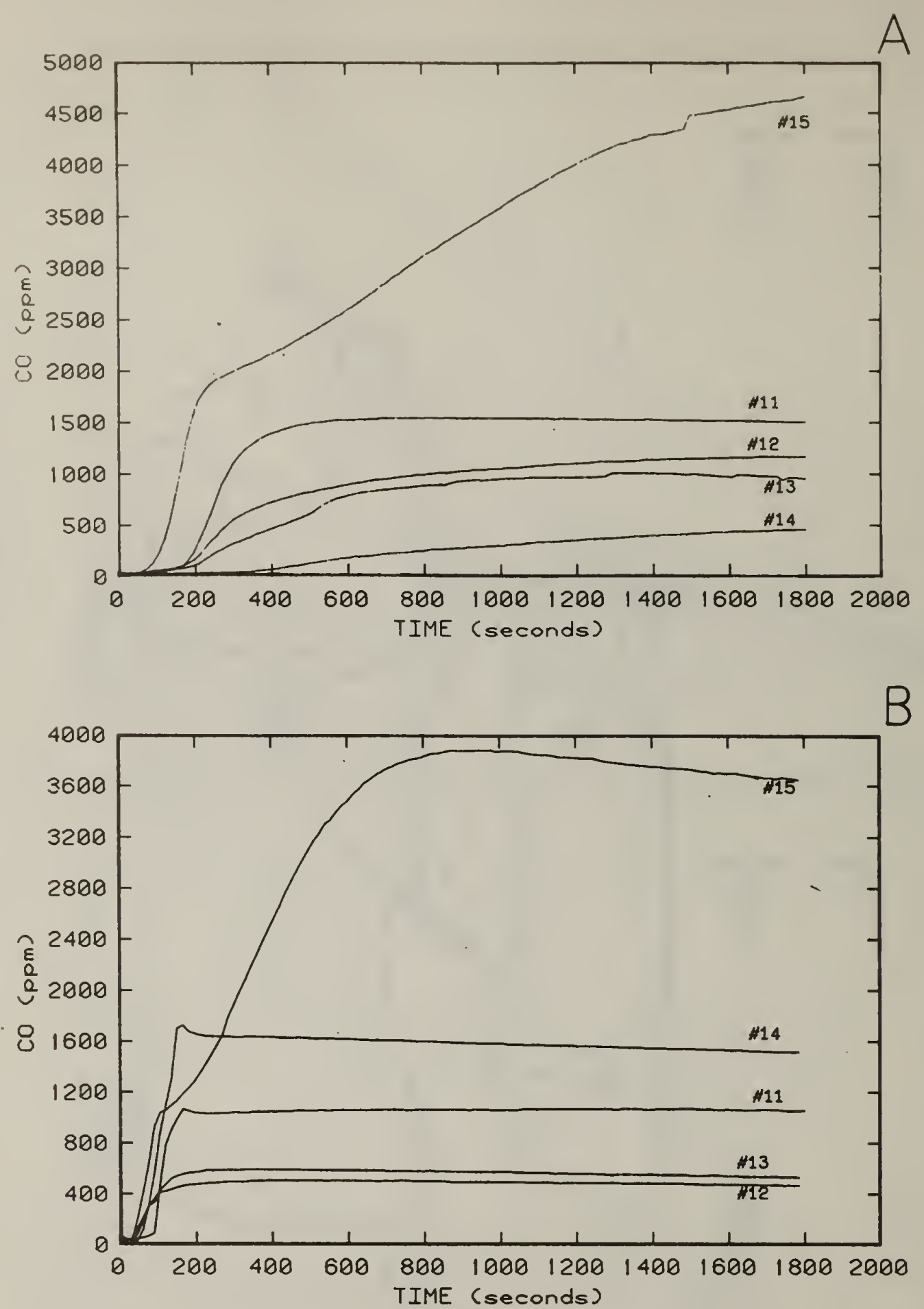

Figure 6. Rate of carbon monoxide generation (ppm) during decomposition of samples $11,12,13,14$ and 15 at mass loading/chamber volume of $30 \mathrm{mg} / \ell$. A - Non-flaming results. B - Flaming results. 


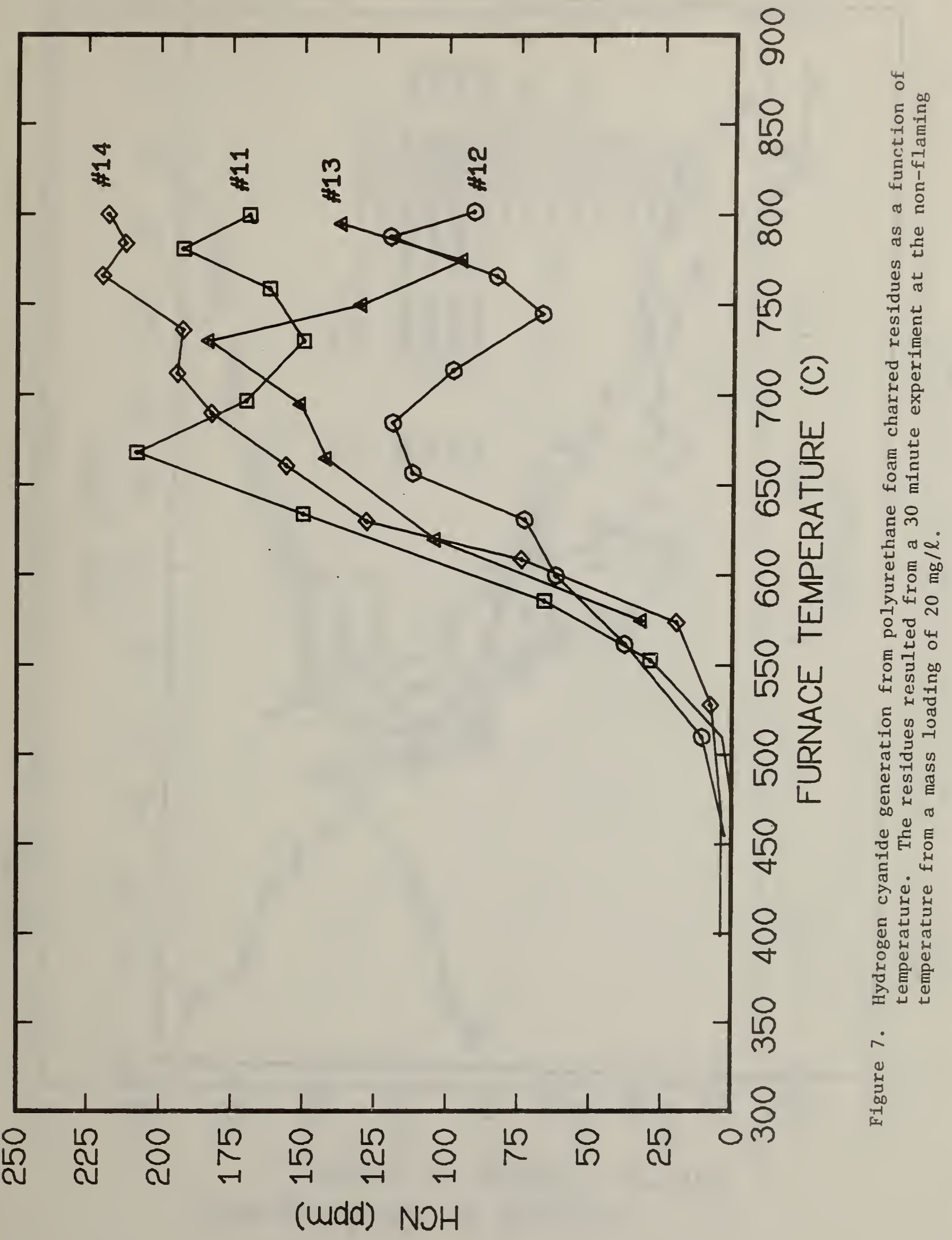




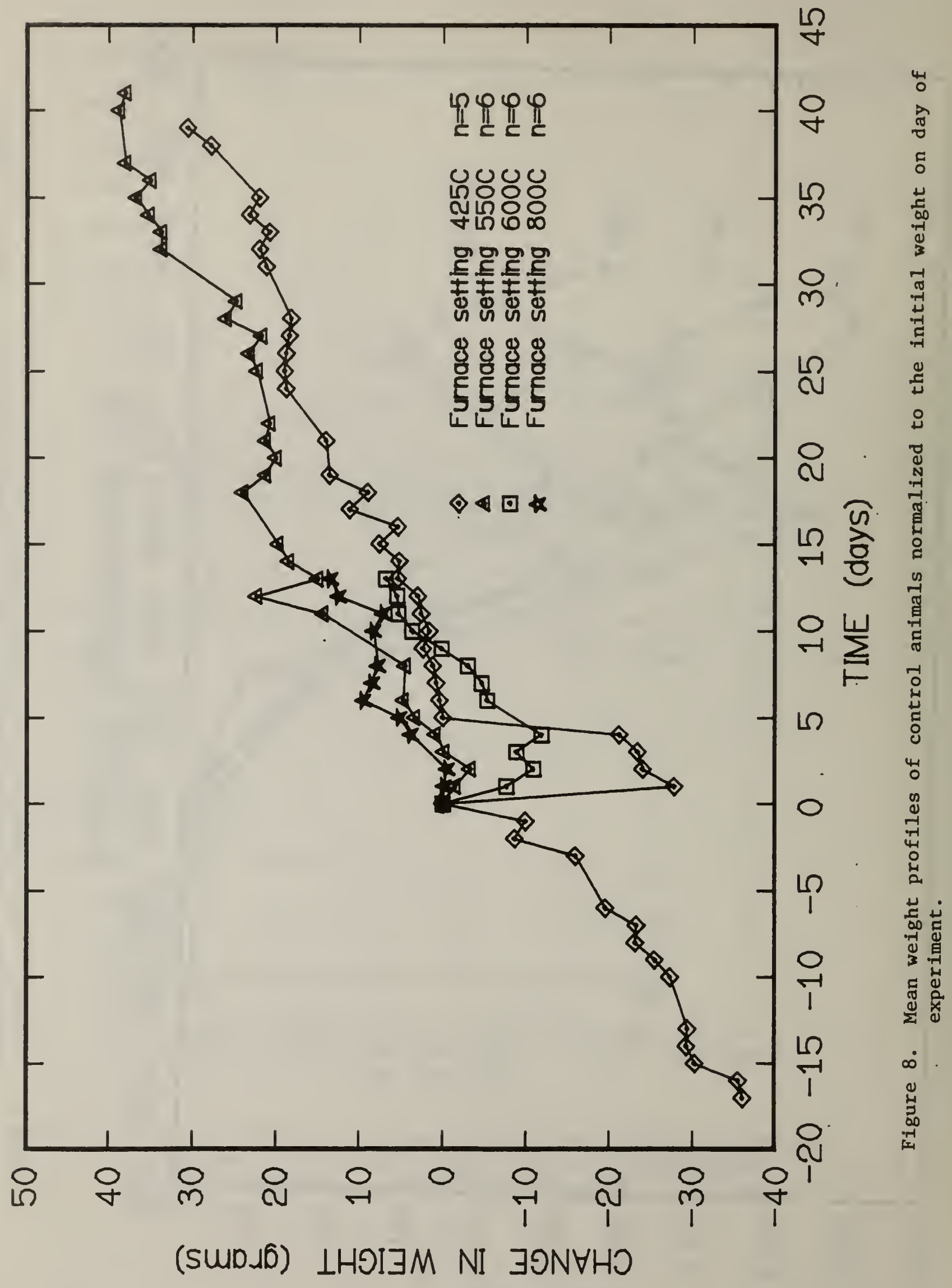




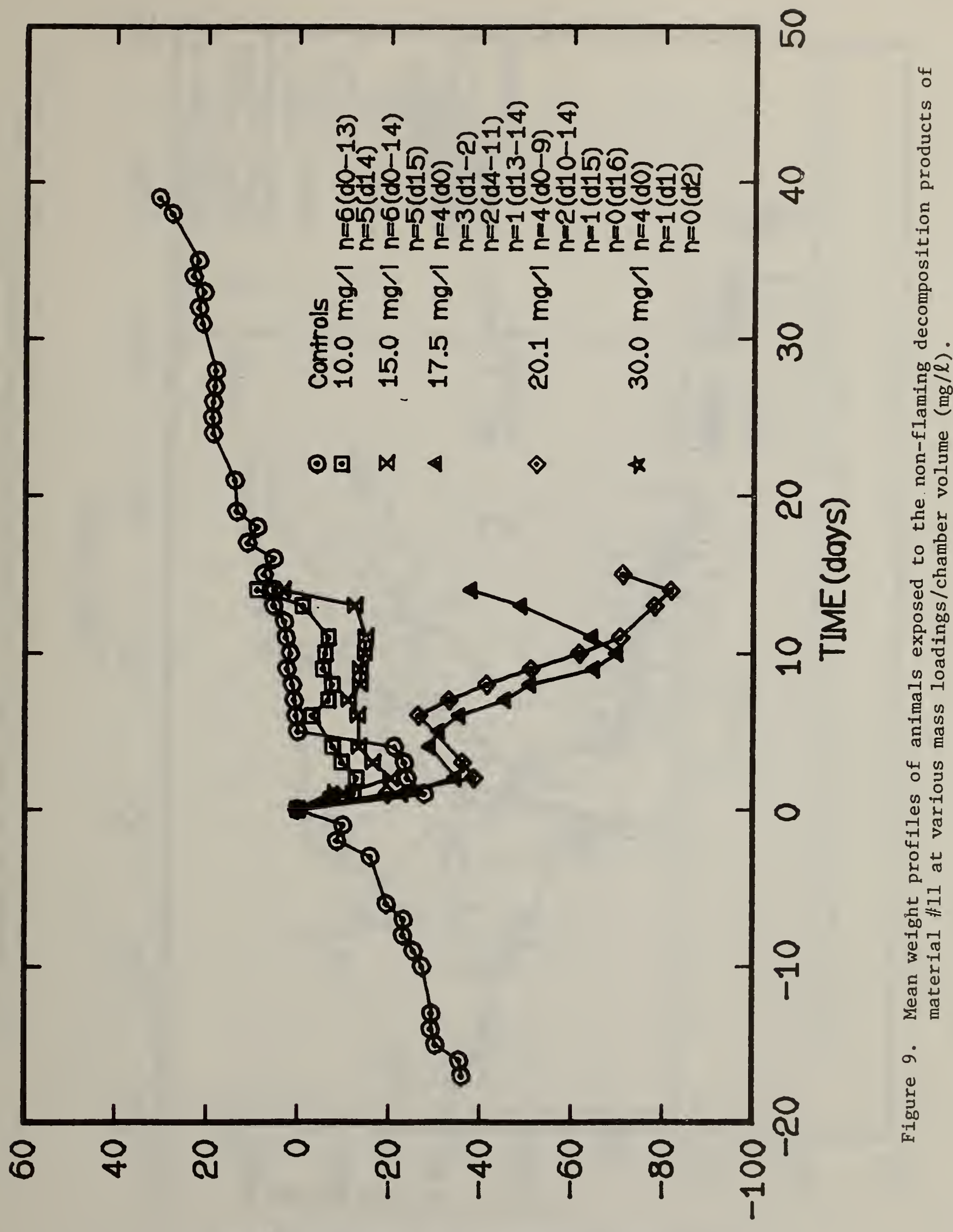

(sWD.b) $\perp H O I \exists M \quad N I J O N \forall H O$ 


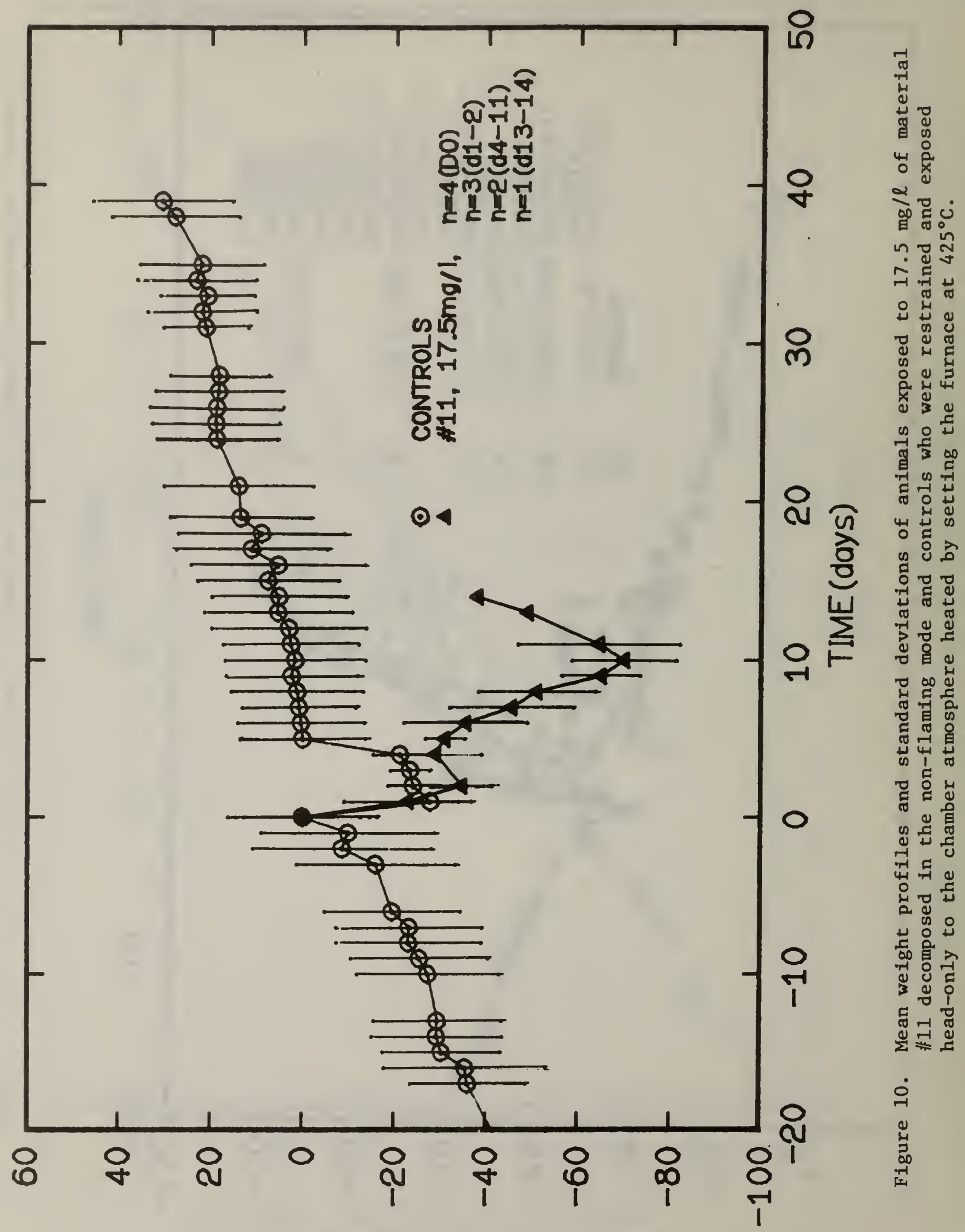

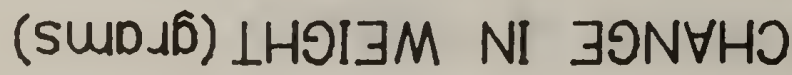




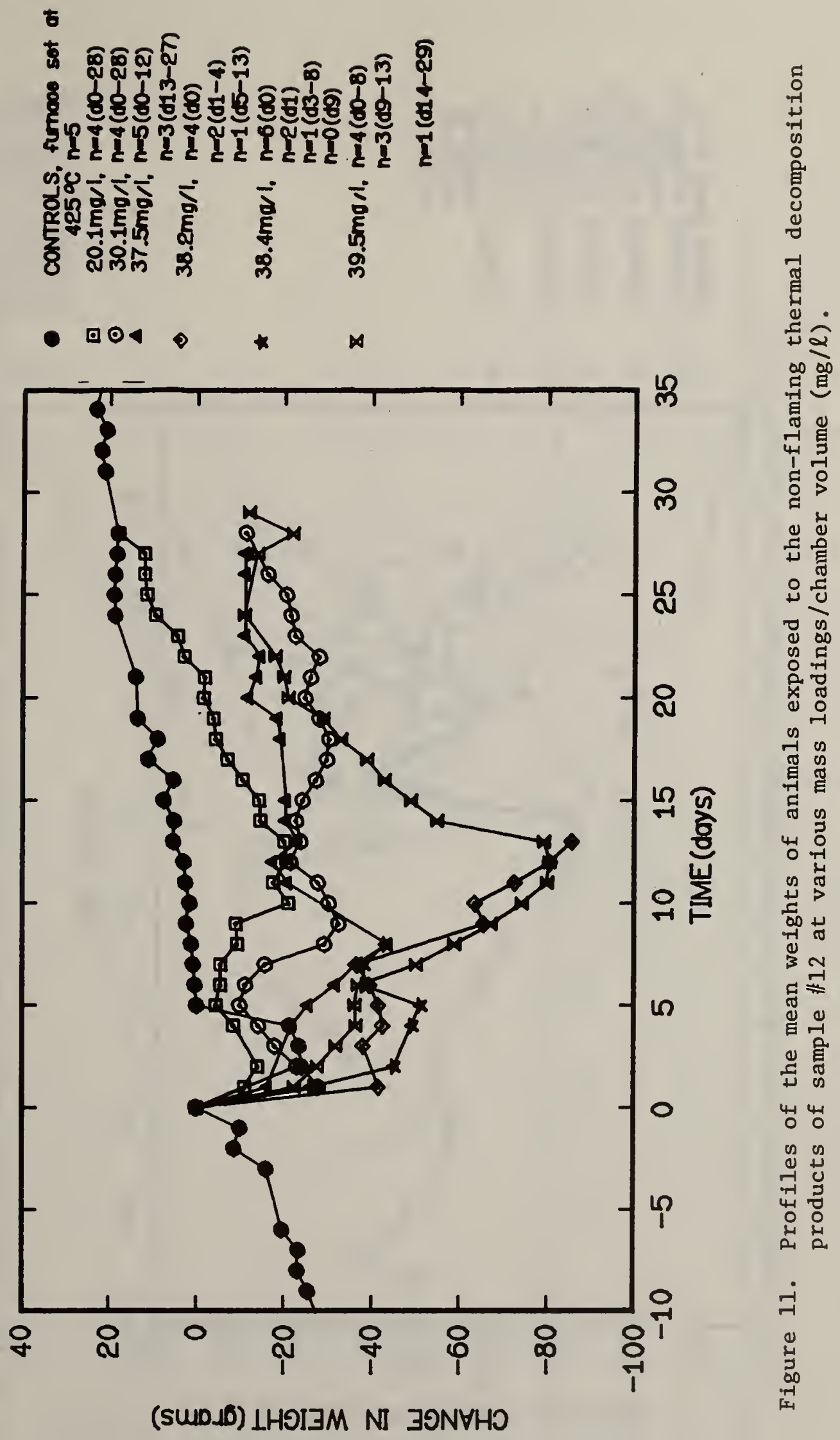




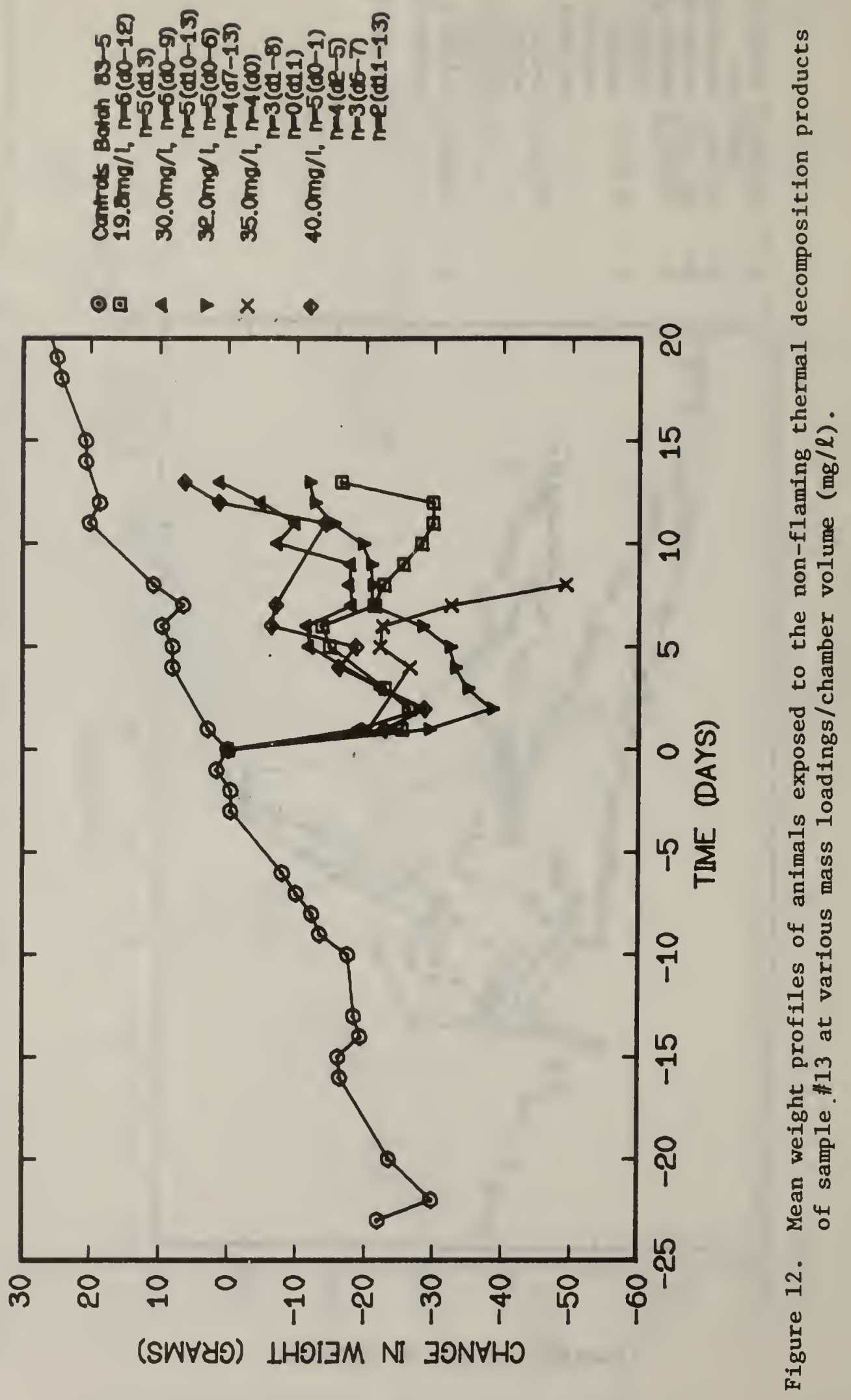




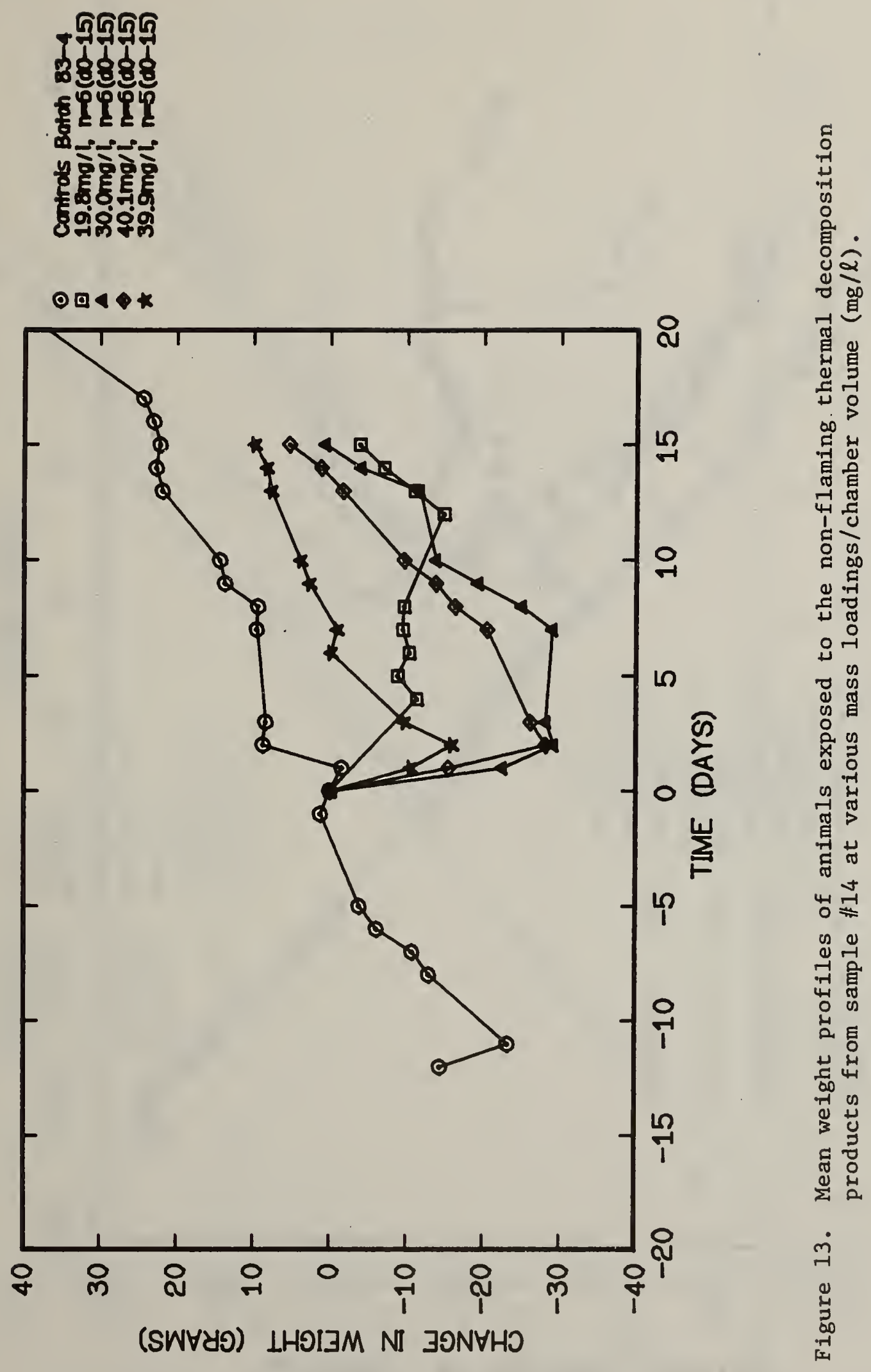




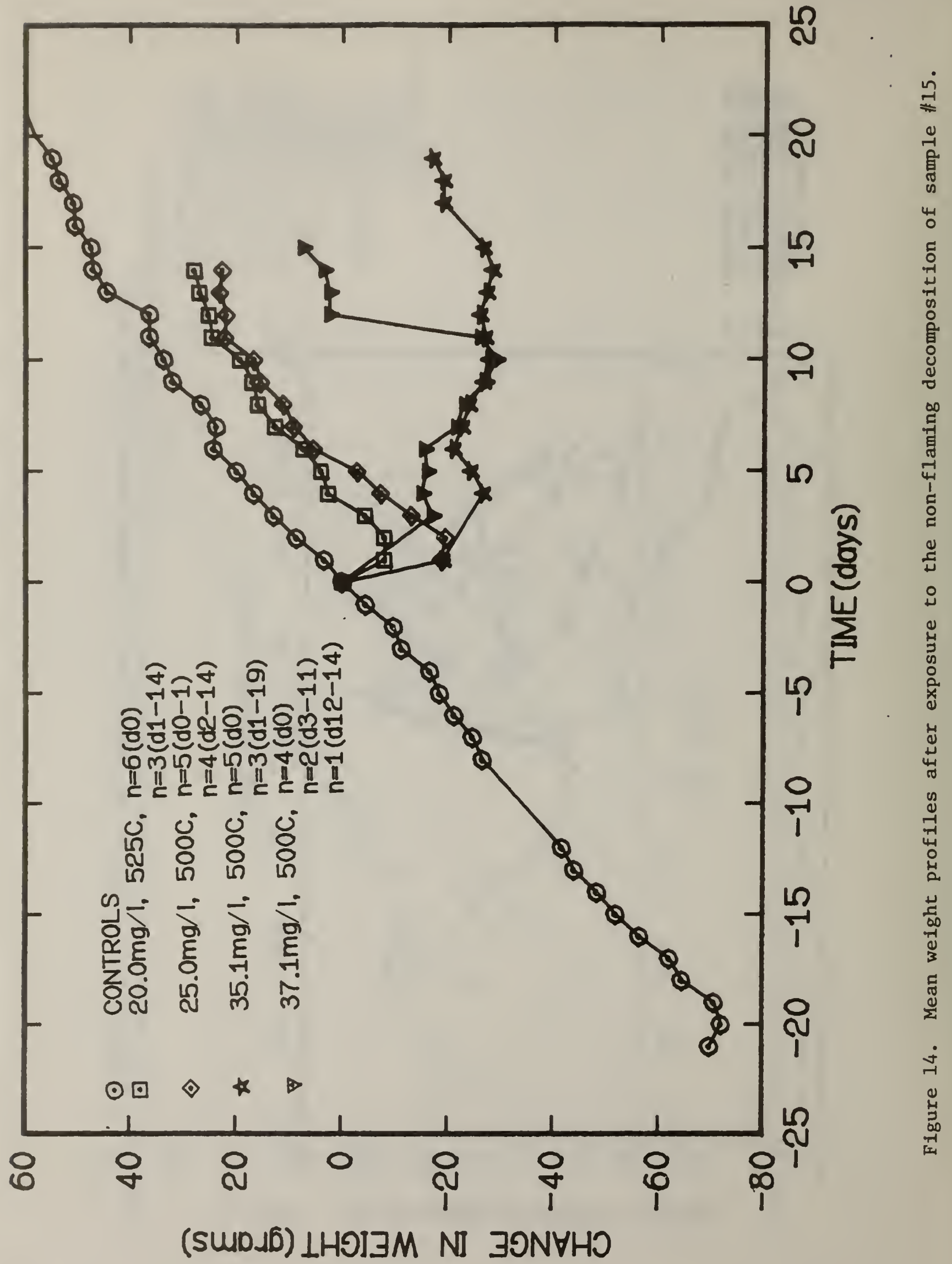




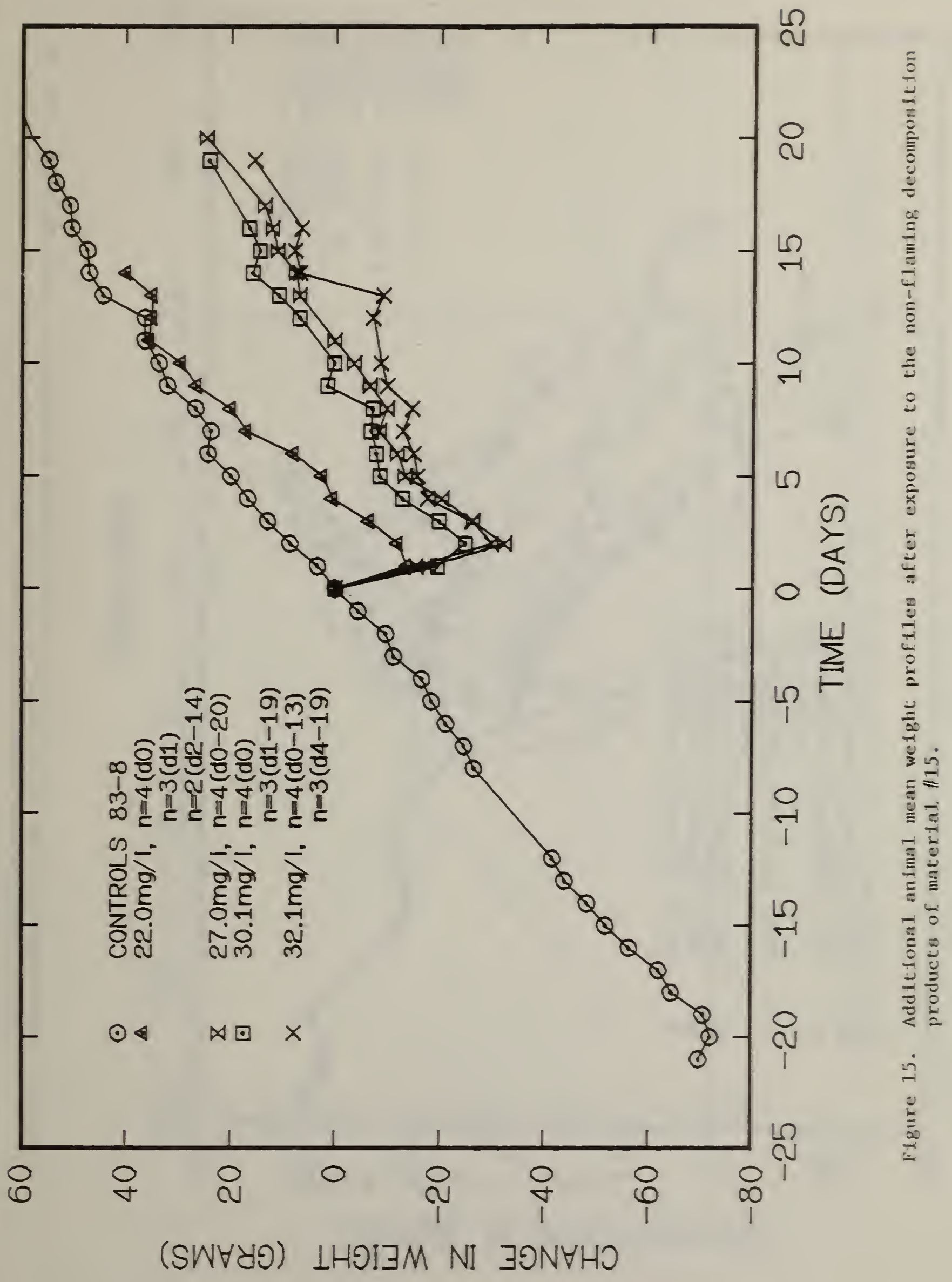




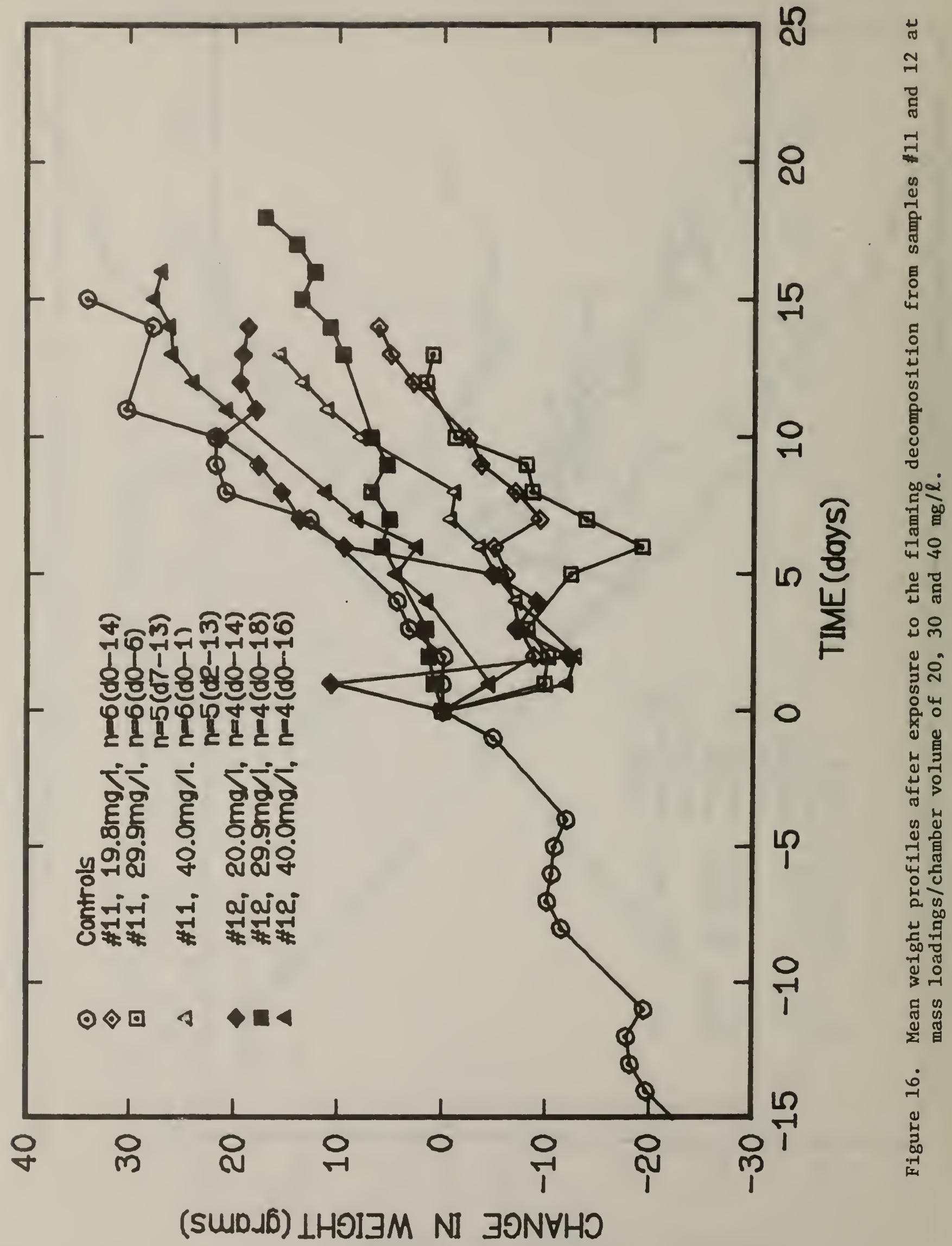




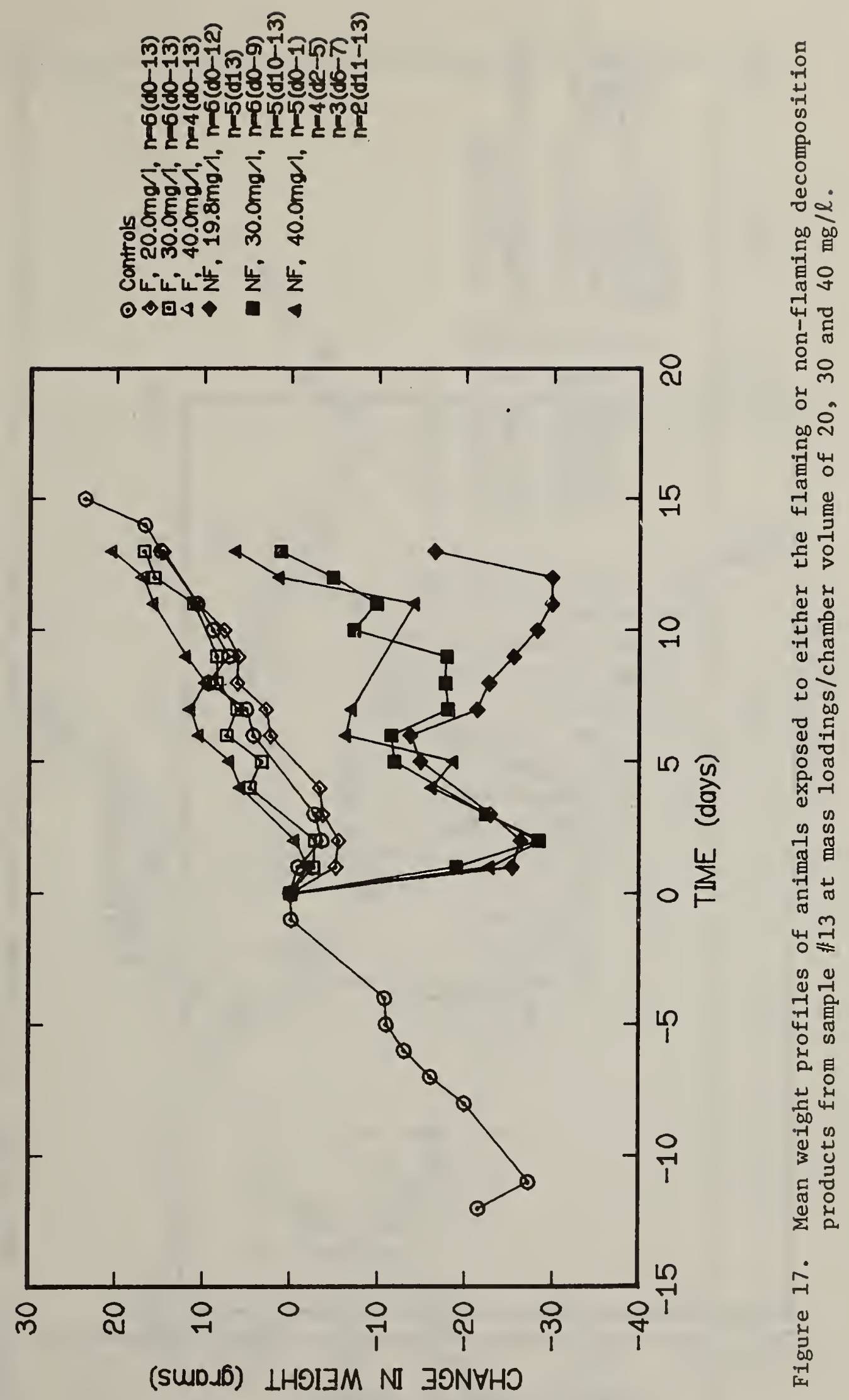




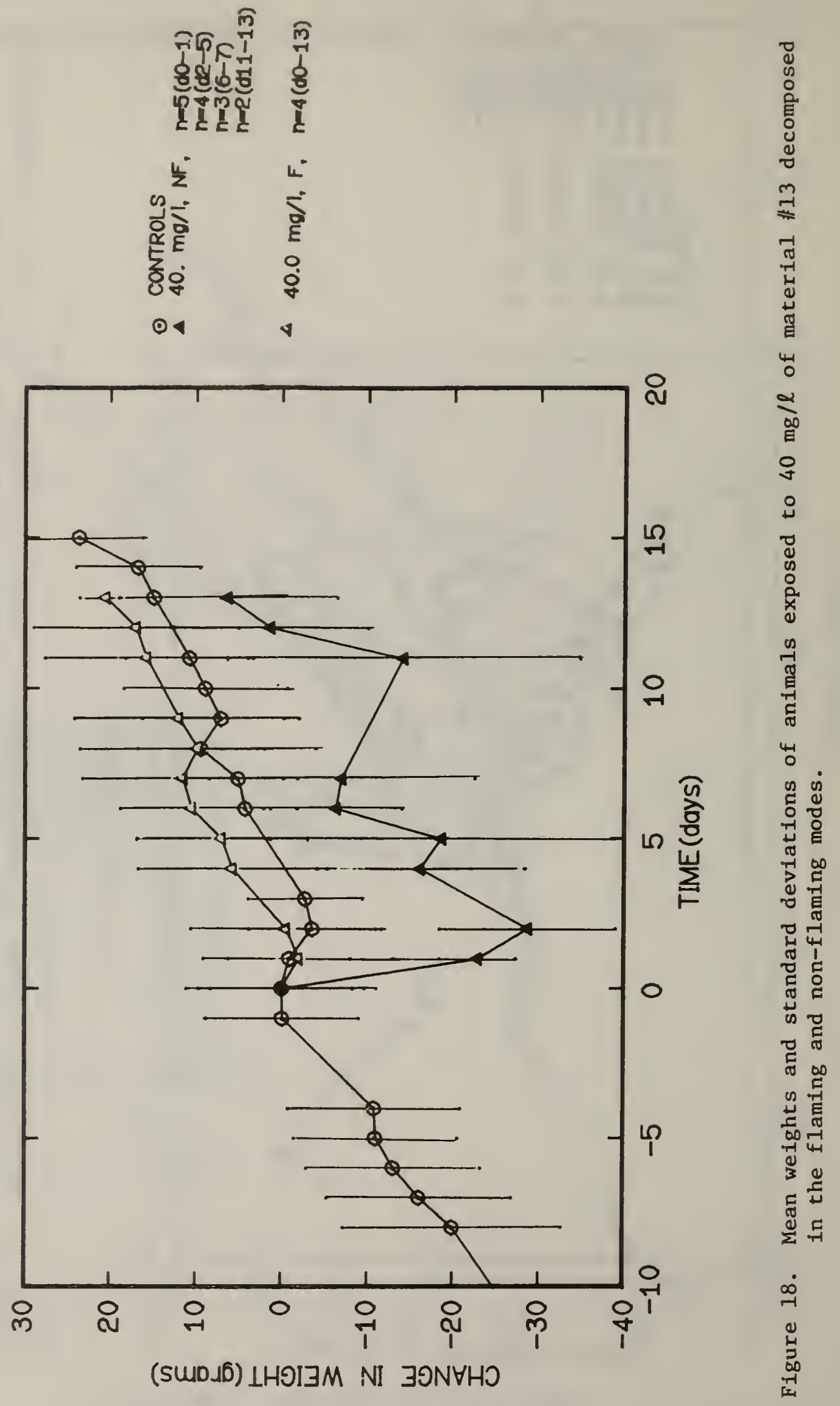




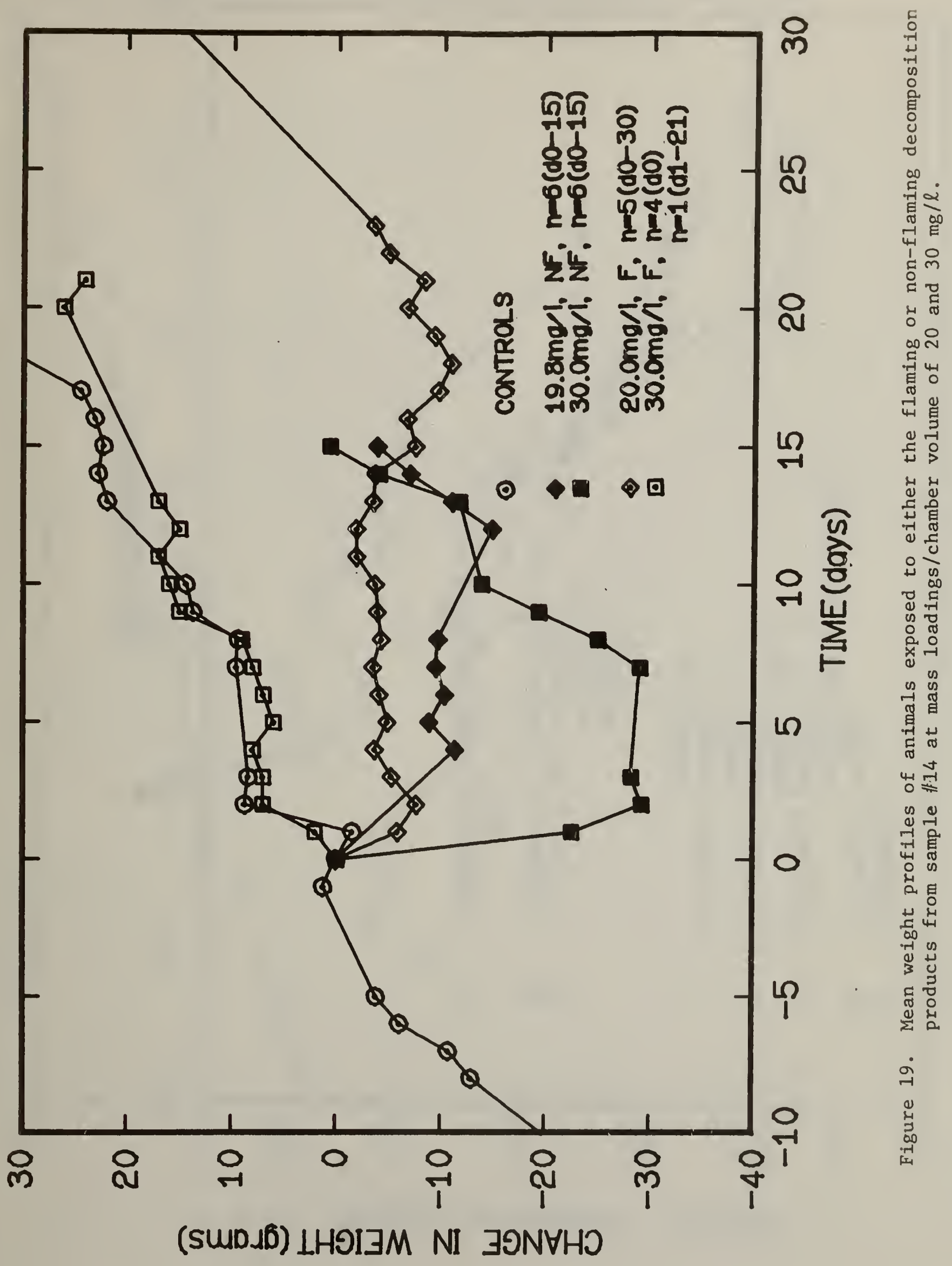




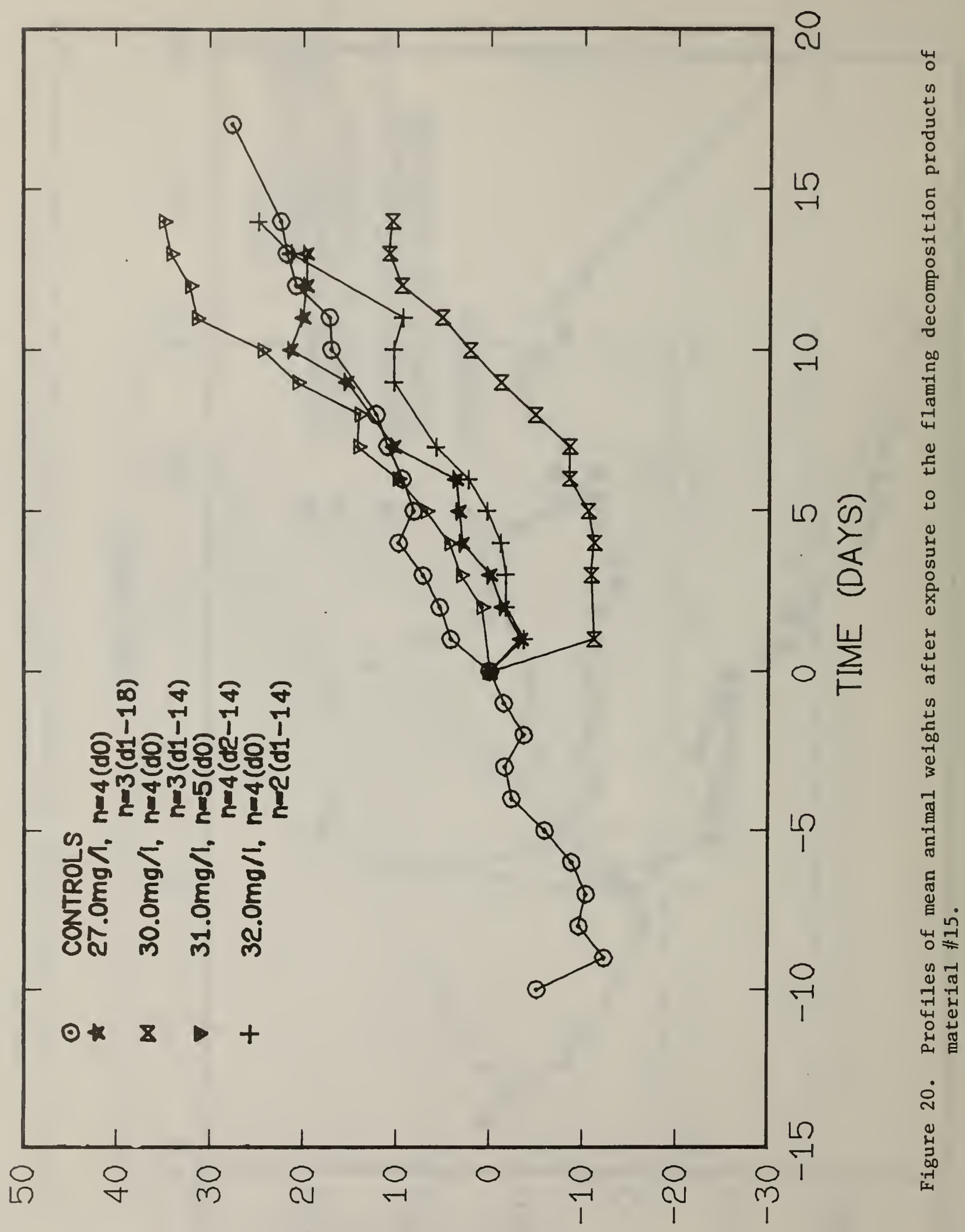

(SWHYO) LHOIJM NI $\exists$ ONHHO 


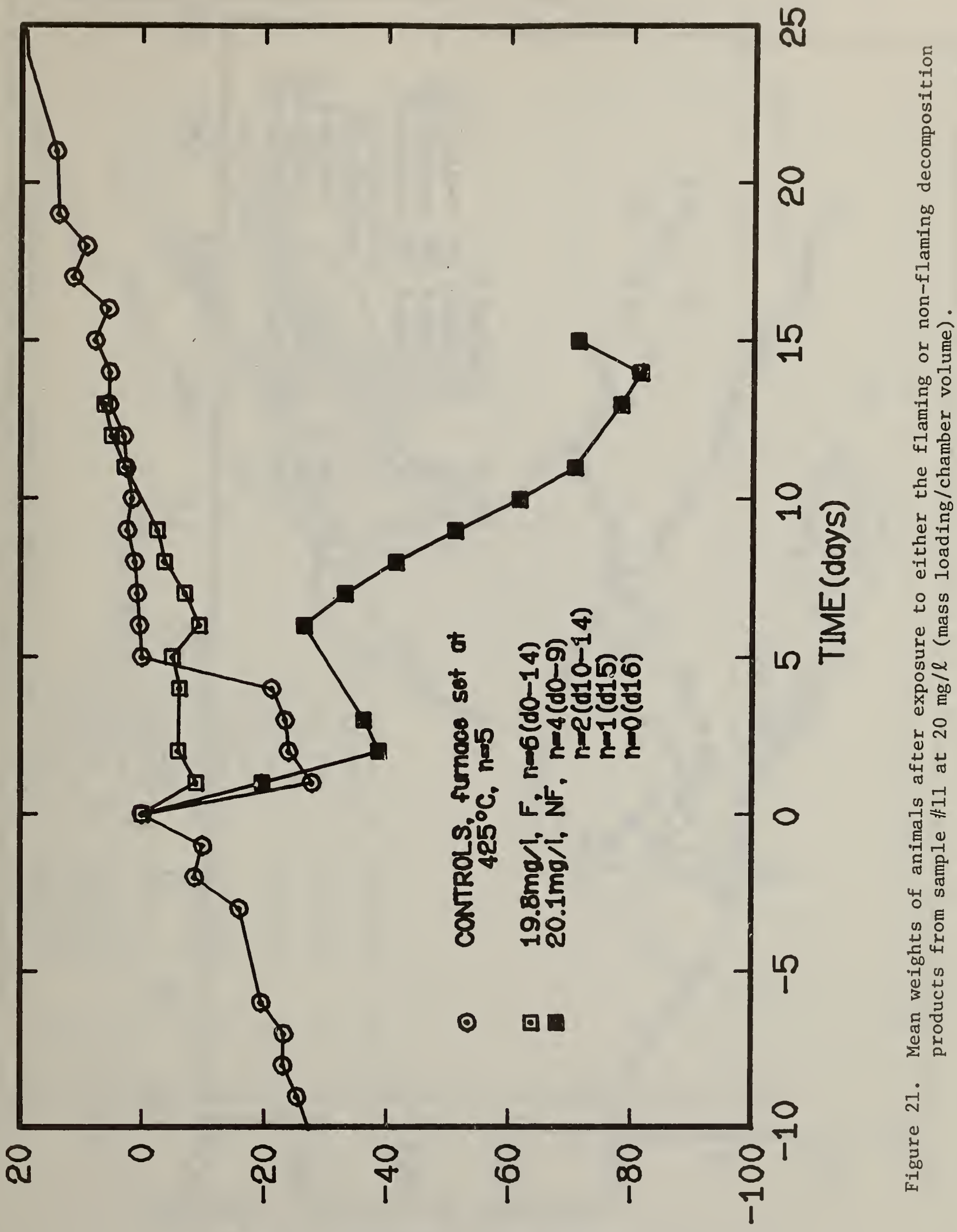

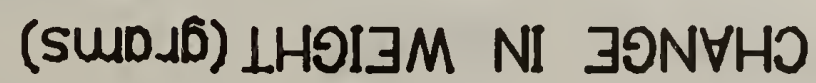




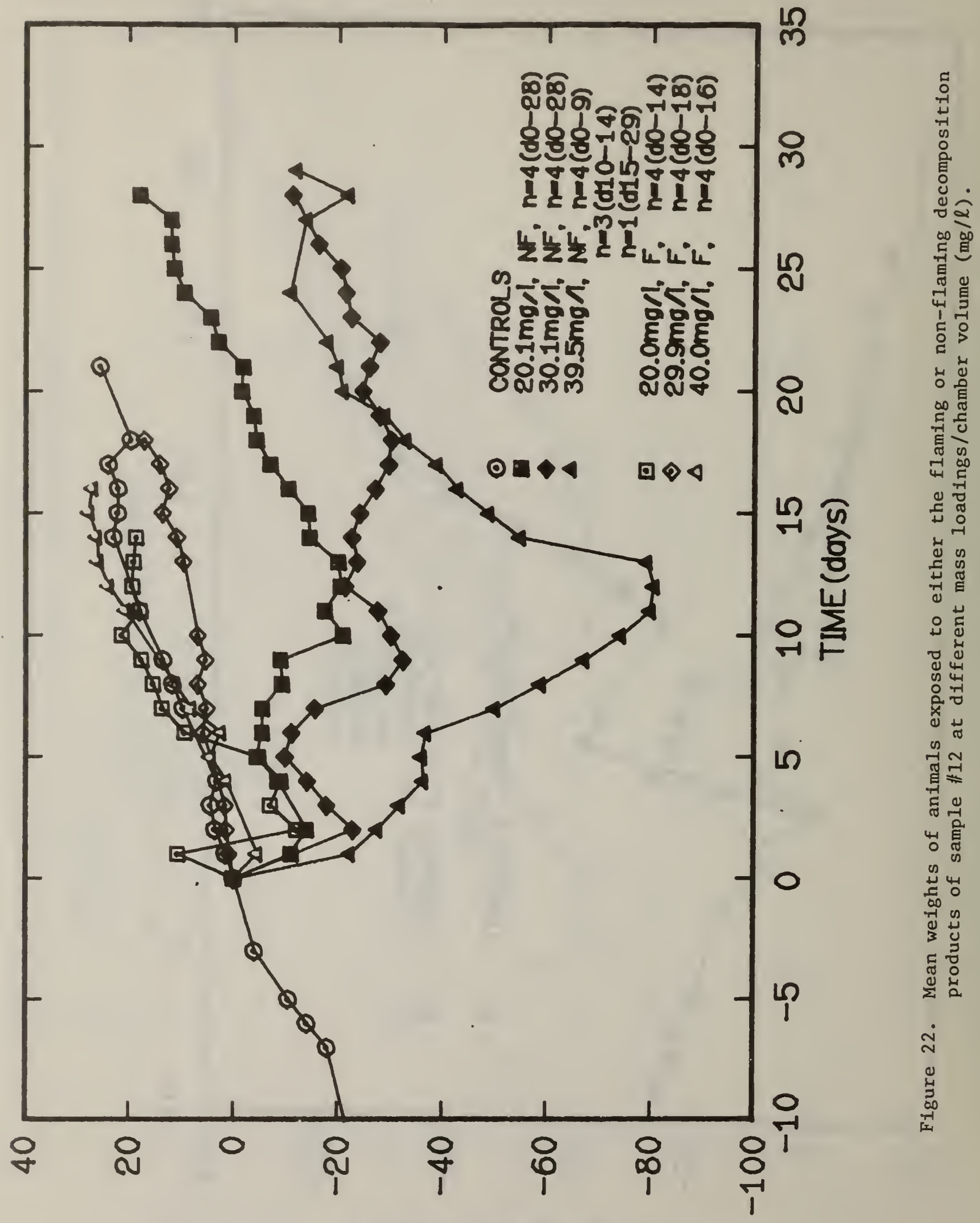

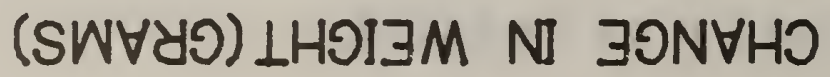




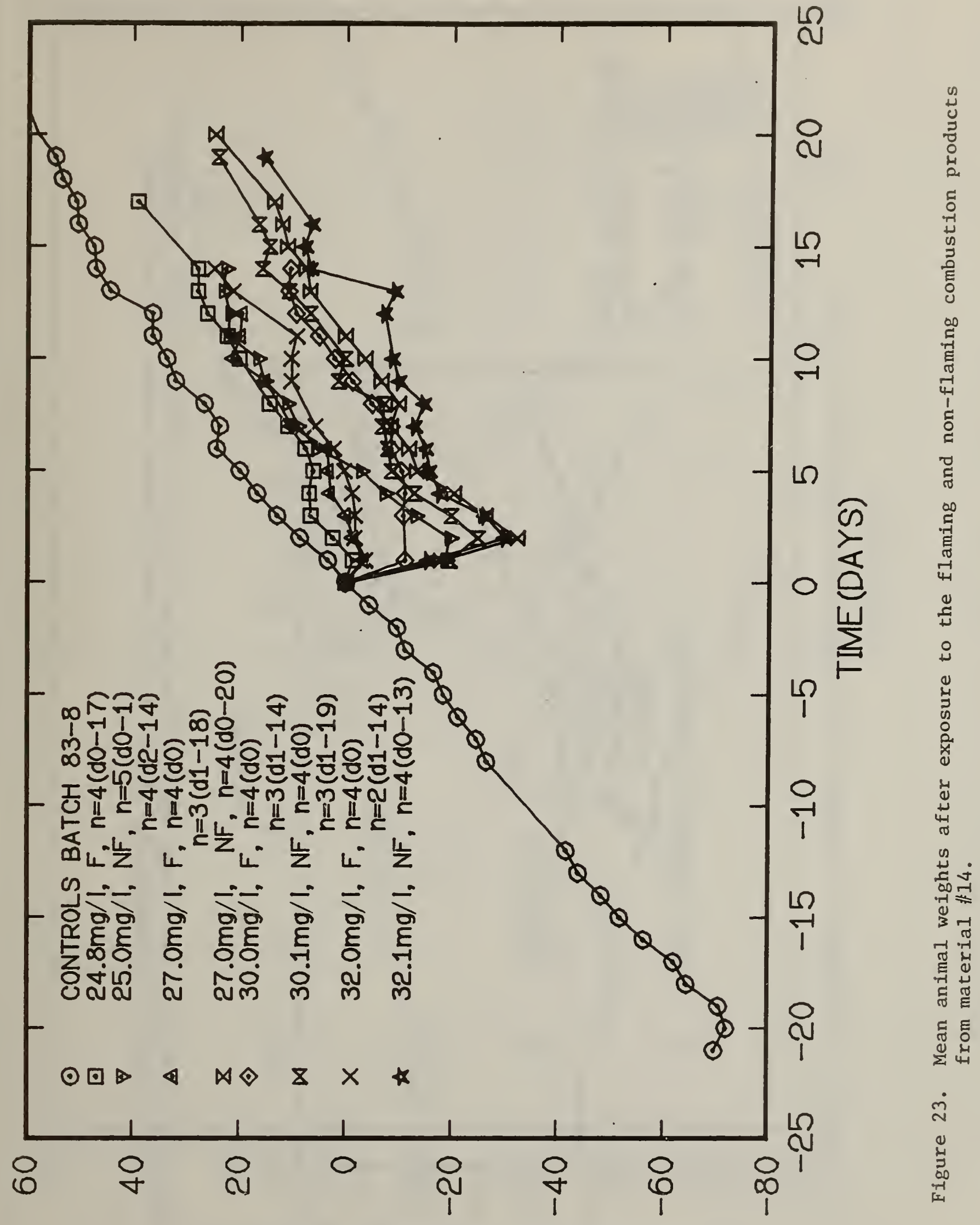

(SW 


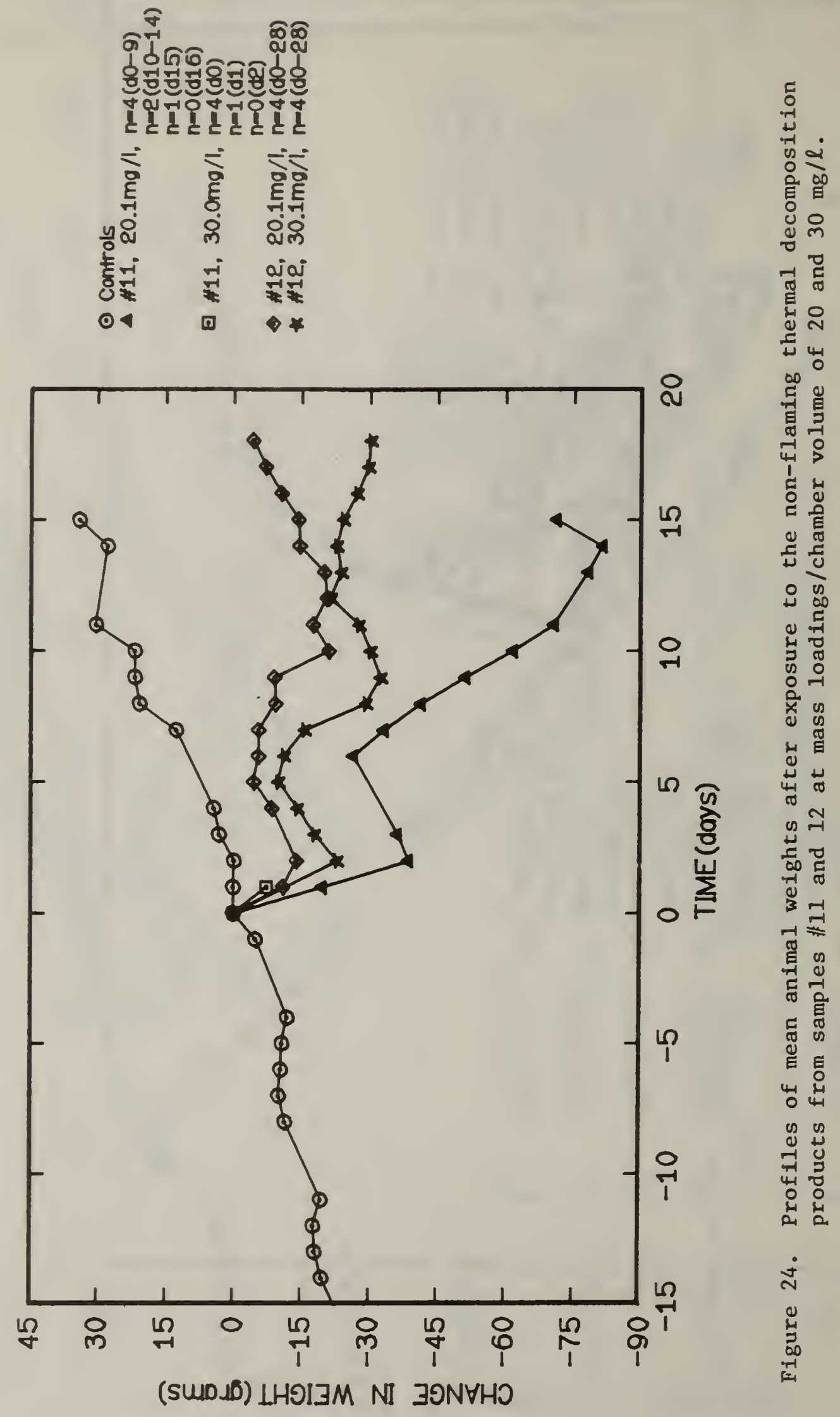




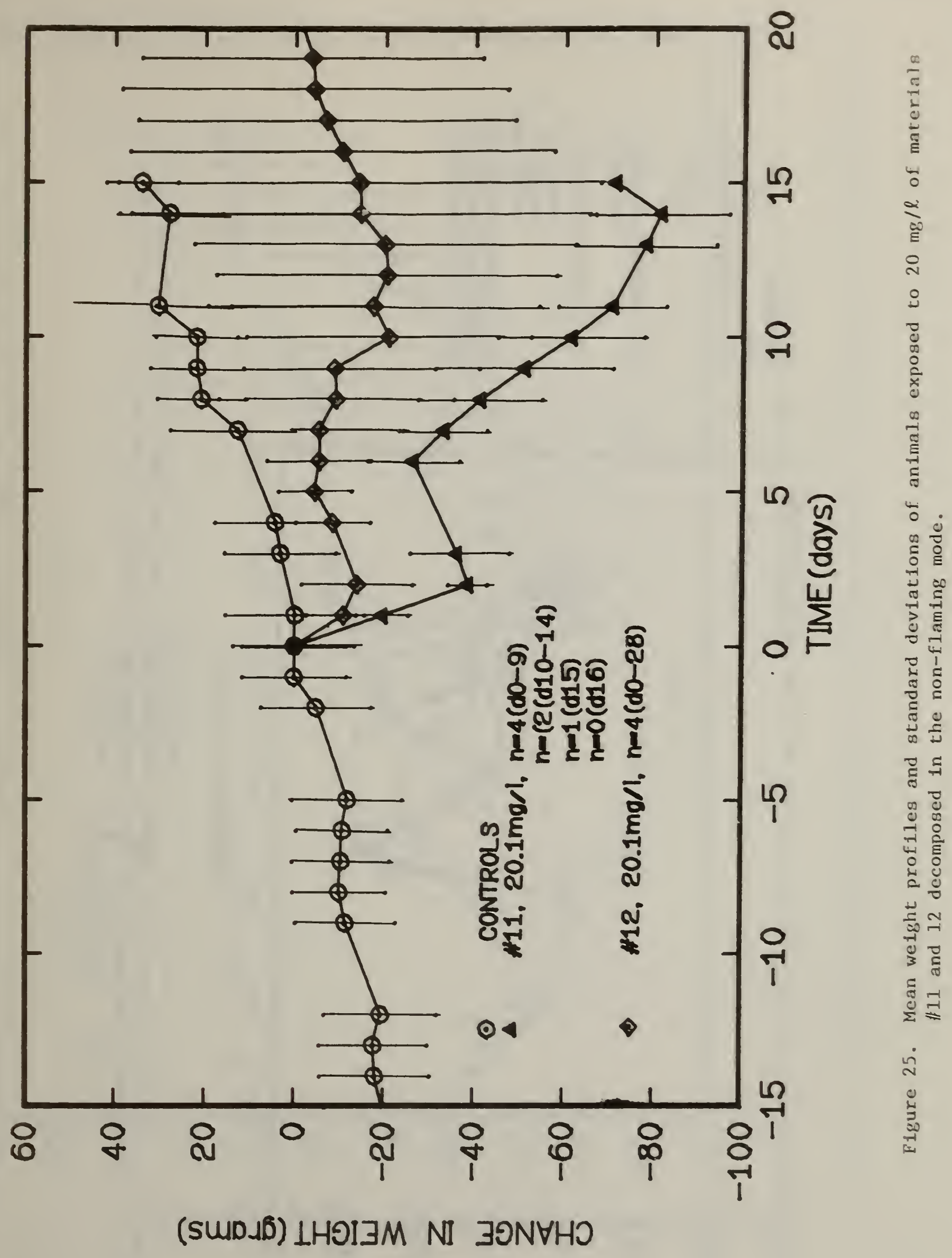




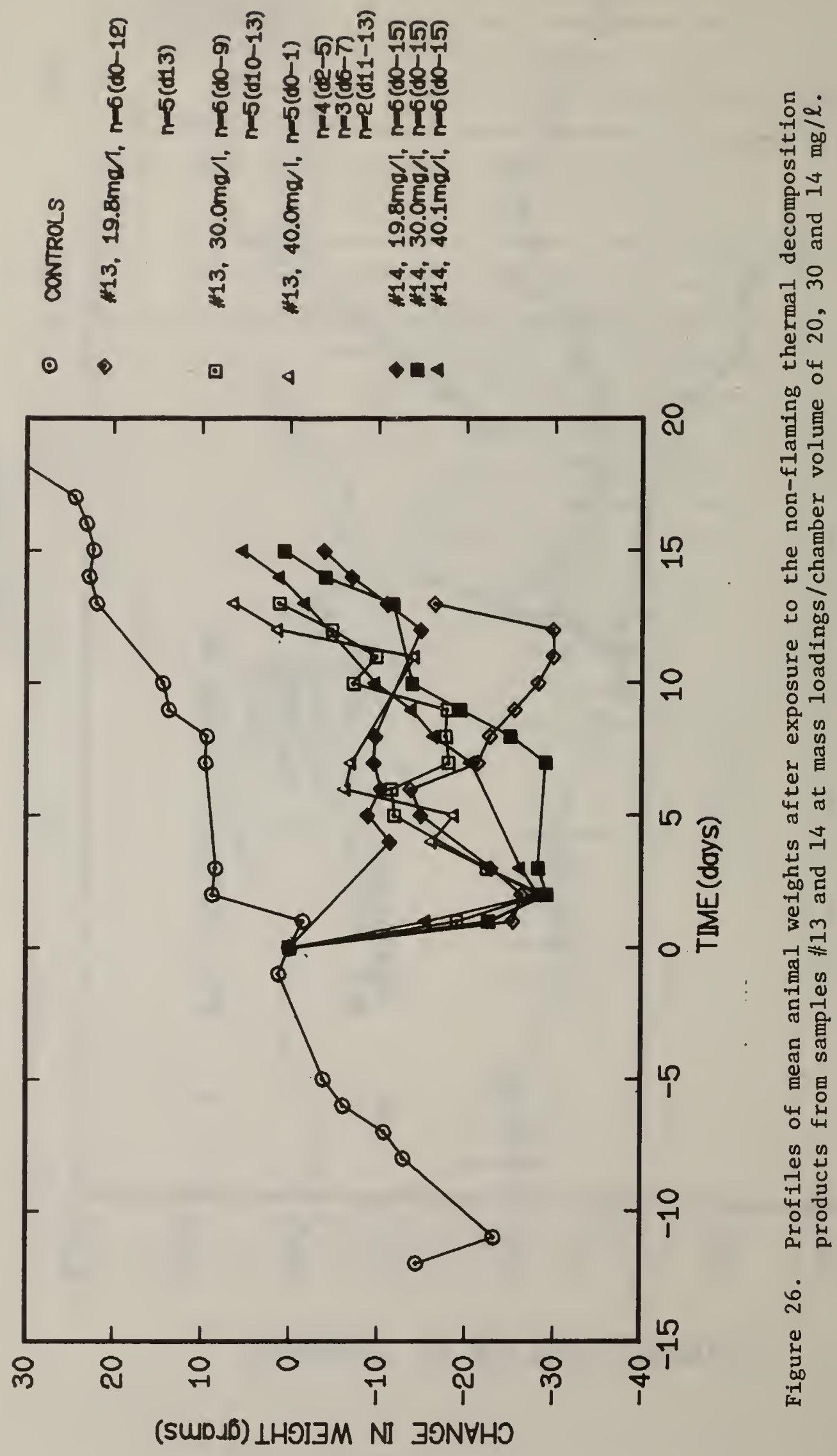




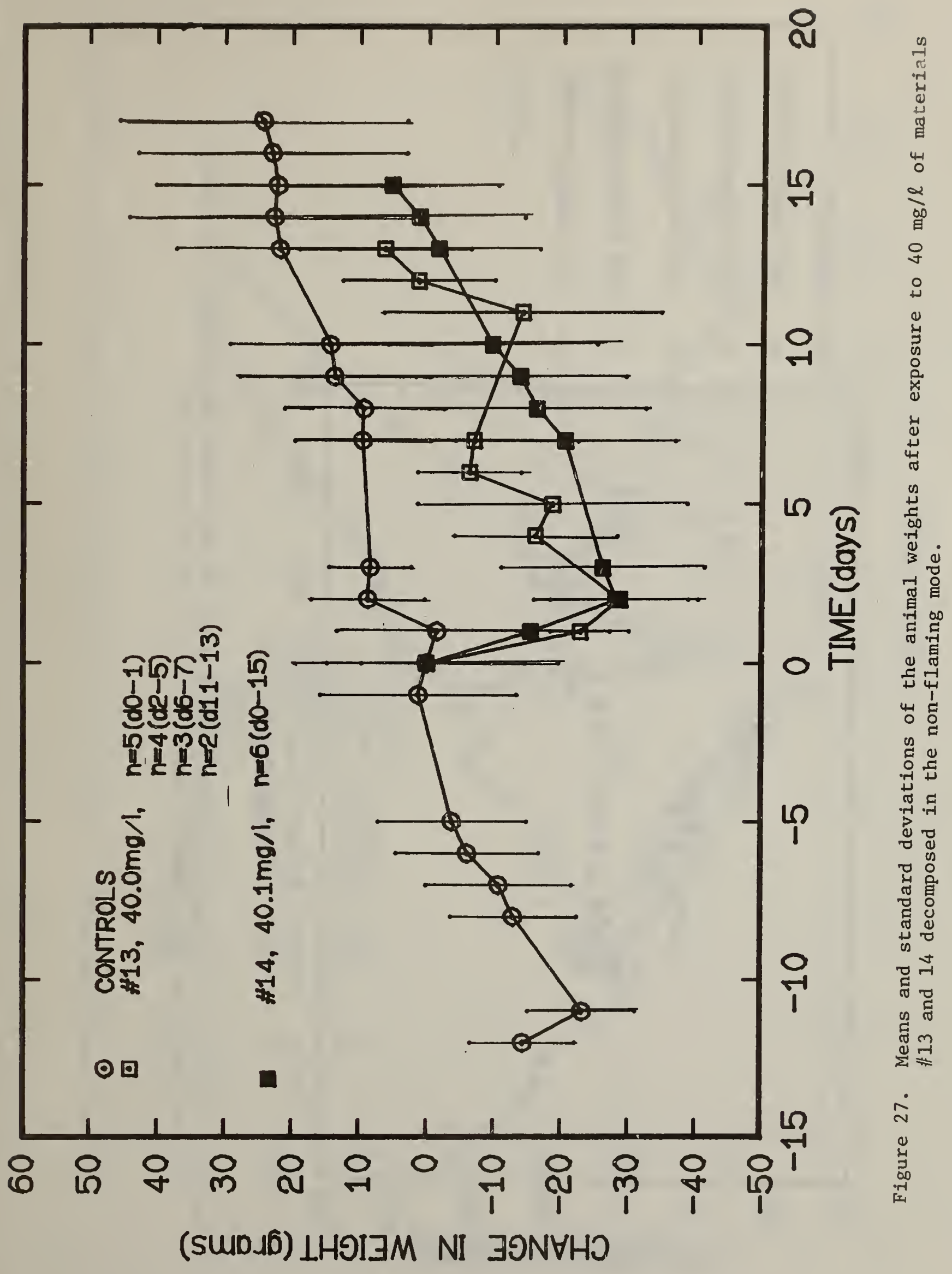




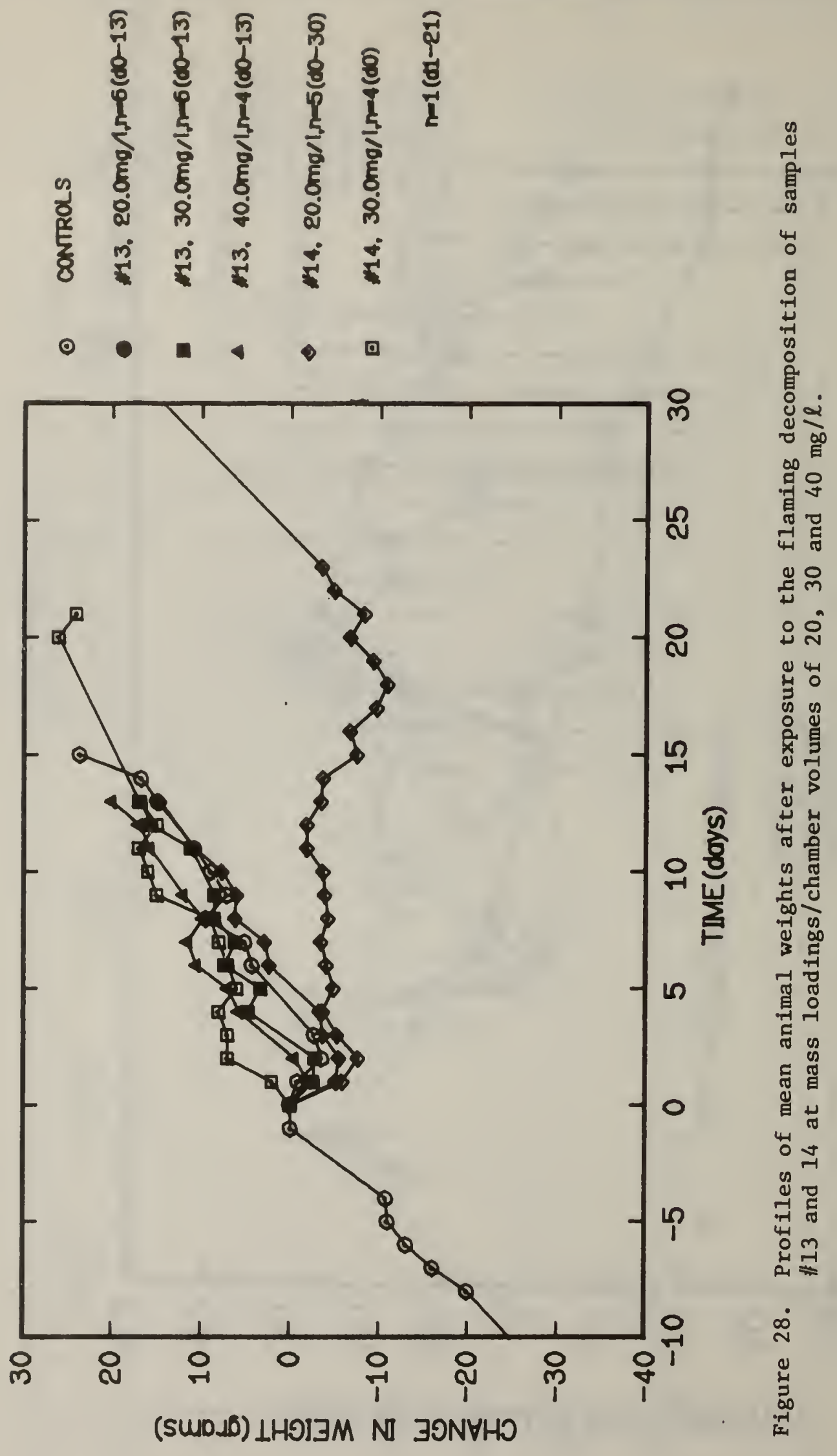




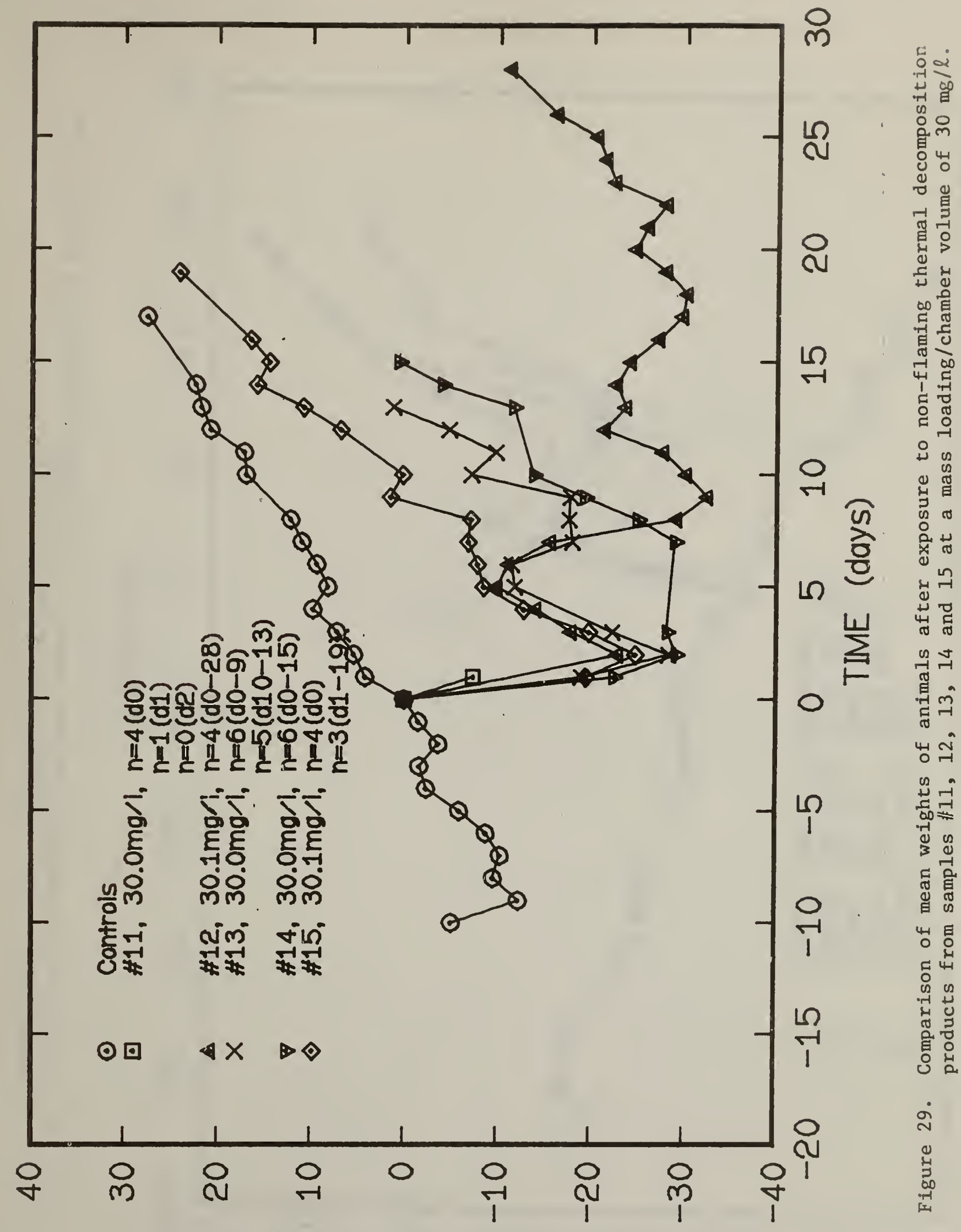

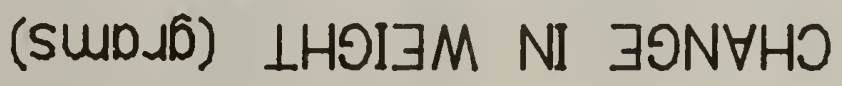




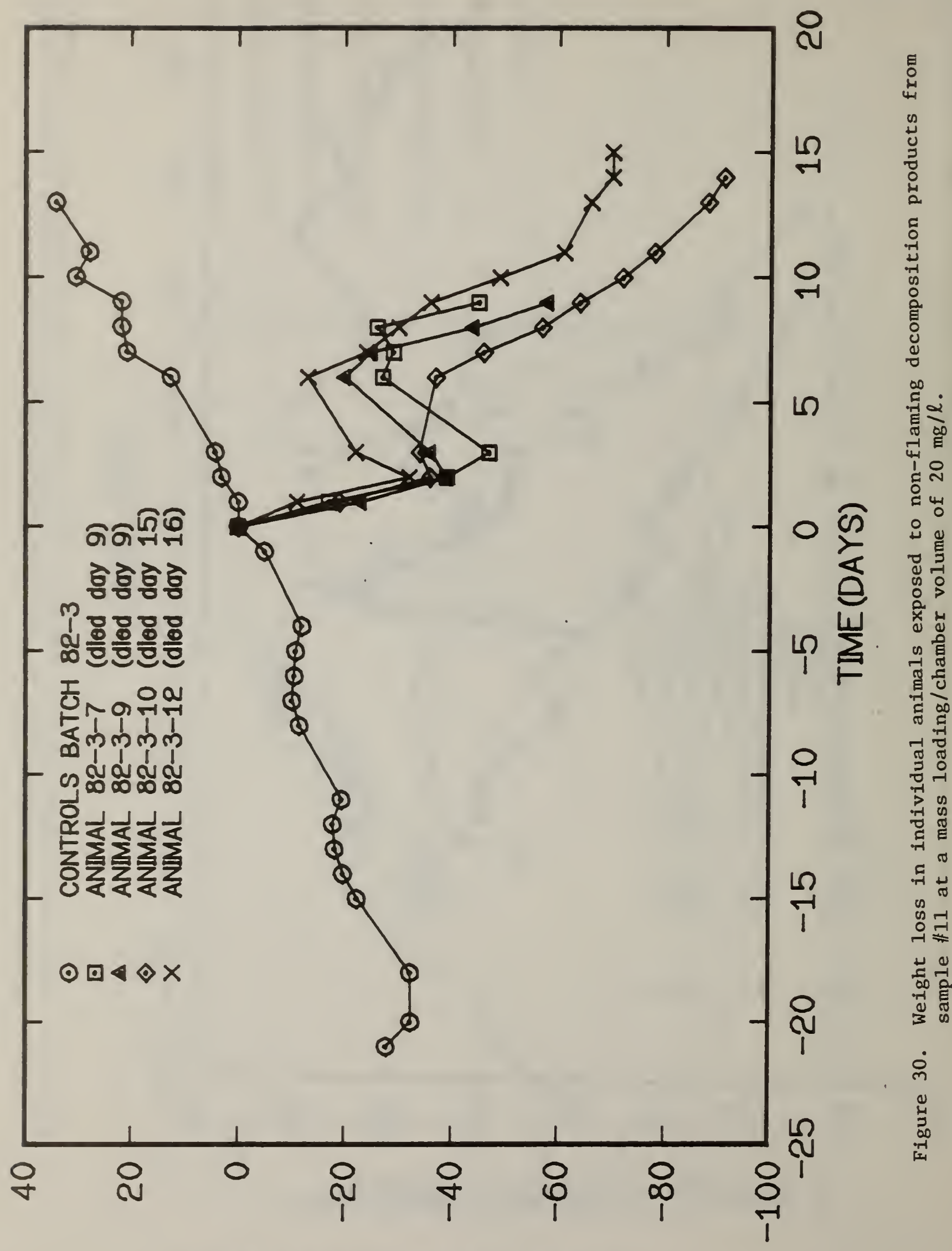

(SW 
APPENDIX 


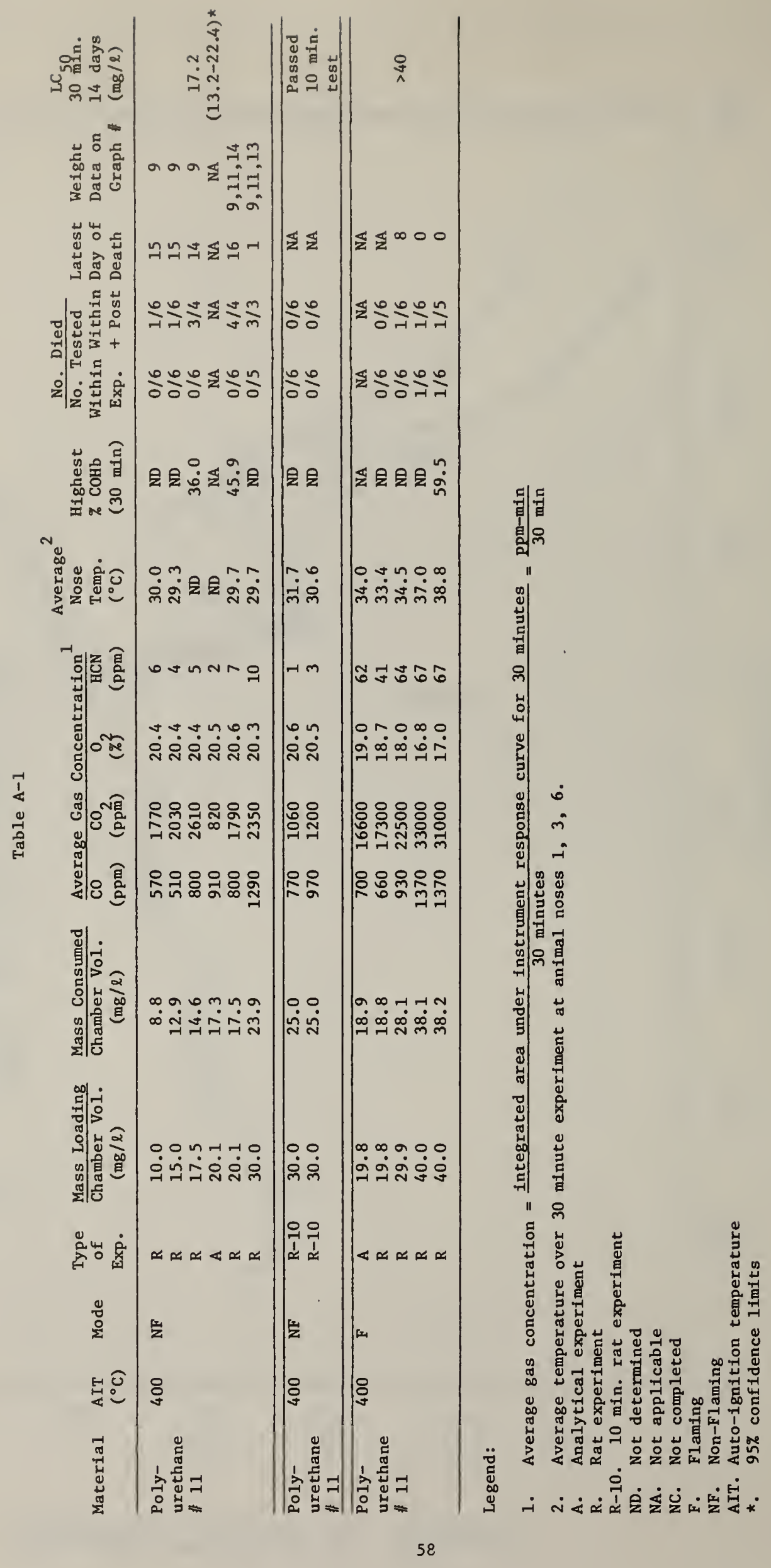




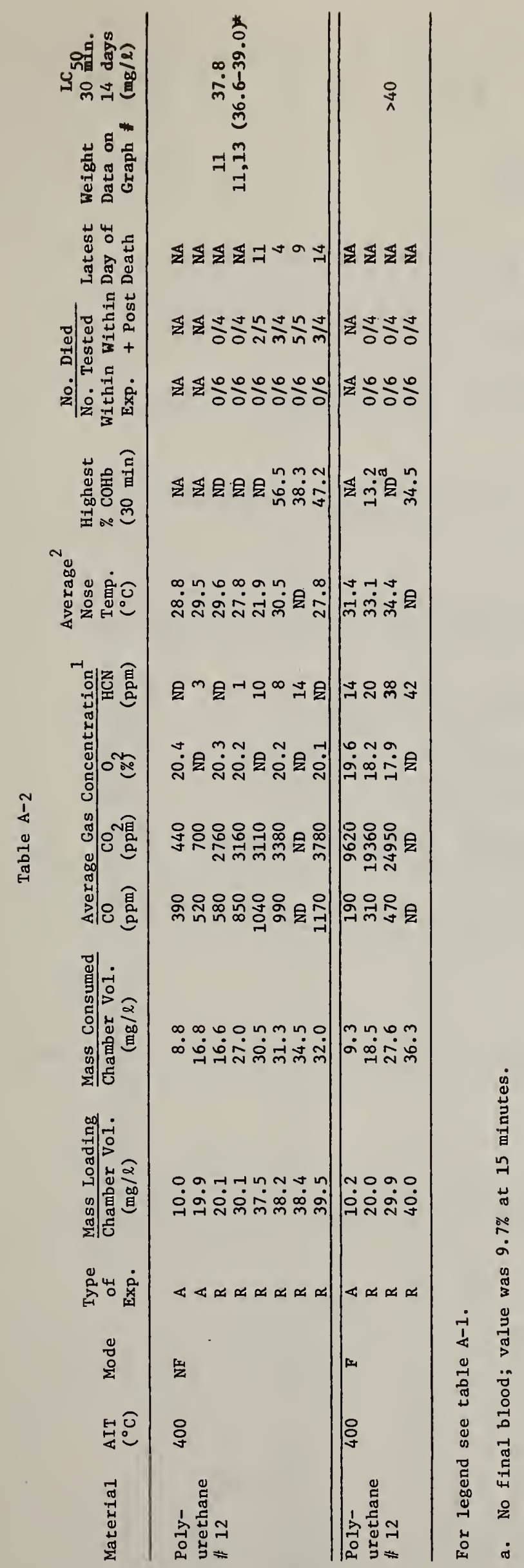




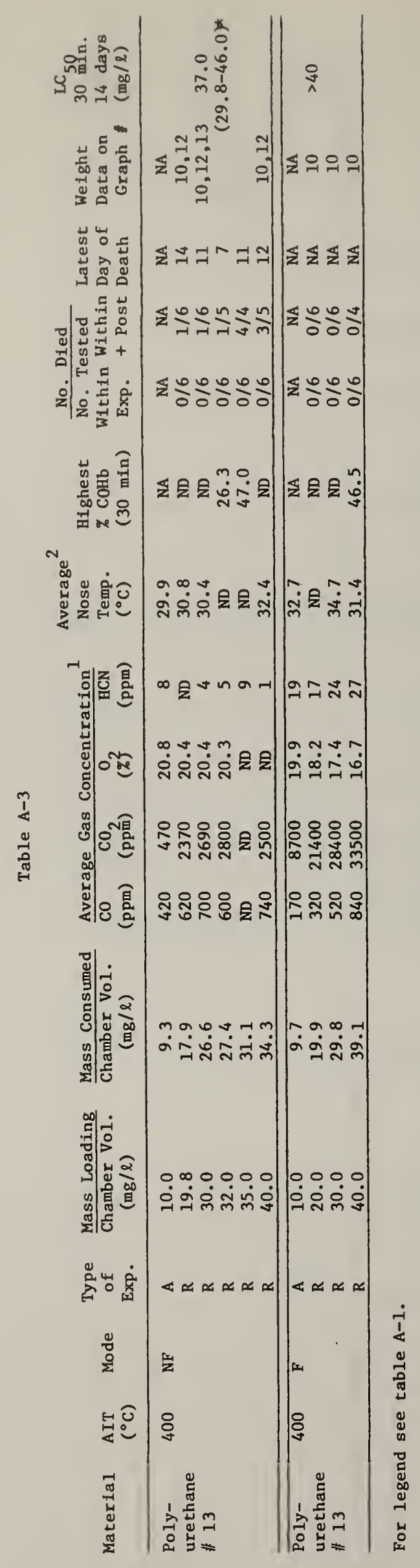




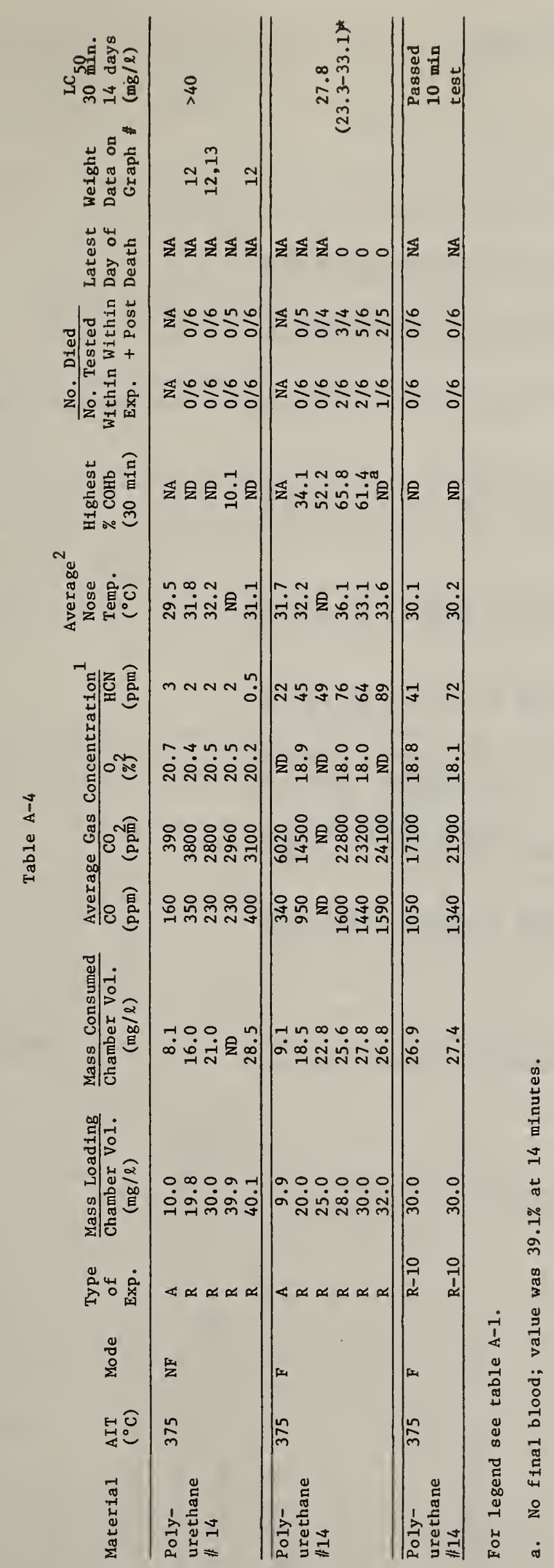




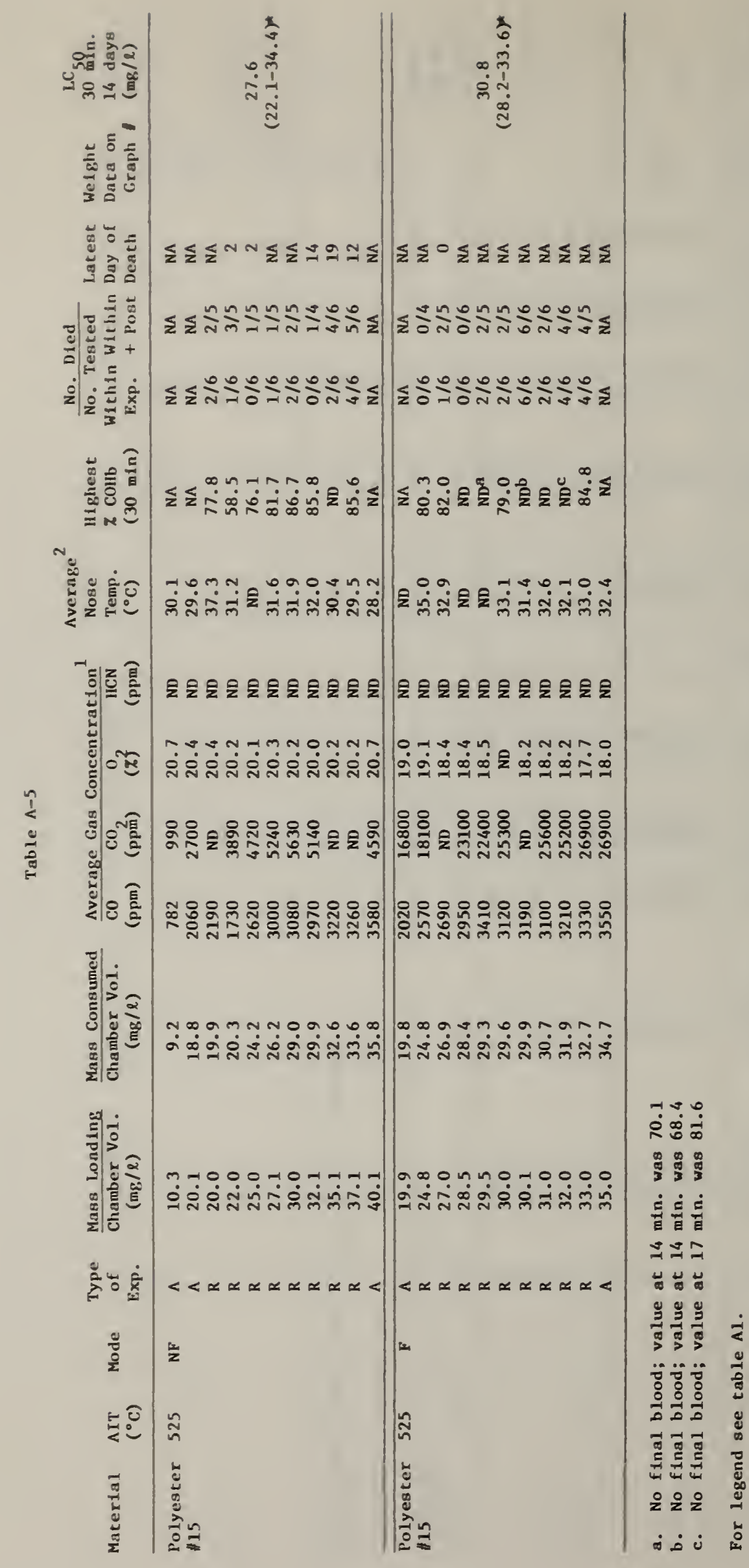


NBS.11 IA IREV. 2.80 I

\begin{tabular}{|c|c|c|c|}
\hline $\begin{array}{l}\text { U.S. OEPT. OF COMM. } \\
\text { BIBLIOGRAPHIC DATA } \\
\text { SHEET (See instructons) }\end{array}$ & $\begin{array}{l}\text { 1. PUBLICATION OR } \\
\text { REPORT NO. } \\
\text { NBSIR } 83-2791\end{array}$ & 2. Performlng Organ. Report No & $\begin{array}{l}\text { 3. Publication Date } \\
\text { November } 198 \mathrm{~s}\end{array}$ \\
\hline
\end{tabular}

4. TITLE AND SUBTITLE

An Acute Inhalation Toxicological Evaluation of Combustion Products from Fire Retarded and Non-Fire Retarded Flexible Polyurethane Foam and Polyester

\section{AUTHOR(S) Barbara C. Levin, Maya Paabo, Mary Lou Fultz,} Cheryl Bailey, Way Yin, and Steven E. Harris

6. PERFORMING ORGANIZATION (If joint or other than NBS, see instructions)

MATIONAL BUREAU OF STANDARDS

DEPARTMENT OF COMMERCE

WASHINGTON, D.C. 20234

9. SPONSORING ORGANIZATION NAME AND COMPLETE ADDRESS (Street, City, Stote, ZIP)

7. Contract Grant No.

CPSC-1AG-74-25

8. Type of Report \& Period Covered

Consumer Product Safety Commission

5401 Westbard Avenue

Bethesda, MD 20207

10. SUPPLEMENTARY NOTES

$\square$ Document describes a computer program; SF-185, FIPS Software Summary, is attached.

11. ABSTRACT (A 200-word or less foctual summary of most significont information. If document includes a significant

The acute inhalation toxicity of the combustion products from selected upholstered furniture filling materials with and without fire retardants was evaluated by the toxicity test method developed by the National Bureau of Standards. The five materials that were evaluated consisted of two different formulations of flexible polyurethane foam (each formulation was supplied in both a fire retarded and non-fire retarded form) and a polyester fiberfill (not fire retarded). Atmospheric concentrations of carbon monoxide, carbon dioxide, oxygen, and hydrogen cyanide in the exposure chamber were monitored throughout the thermal decomposition of the materials. In addition, time-toignition, rate of heat release, hydrogen cyanide generation via a two phase decomposition procedure and $x$-ray fluorescence measurements were performed. The LC50 (30 minute and 14 day) values did not distinguish any of the materials as being significantly more toxic than the others. In the worst case, one of the fire retarded polyurethane foams was only a factor of two more toxic than its untreated counterpart. Only the fire retarded foams and the polyester caused deaths of the Fischer 344 rats during the 30 minute exposures. Extensive weight loss and post-exposure deaths occurred after exposure to the combustion products from all the materials. Animal deaths during or following exposure to the polyurethane cannot be attributed to carbon monoxide or hydrogen cyanide alone. Deaths during exposure to the polyester combustion products appear to be more directly related to the concentrations of carbon monoxide.

12. KEY WORDS (Six to twelve entries; alphobetical order; capitalize only proper names; and seporate kev words by semicolons Carbon monoxide; combustion products; fire retardants; heat release; hydrogen

cyanide; inhalation; polyester; polyurethane foams; toxicology; weight loss

\section{AVAILABILITY}

X Unlimited

$\square$ For Official Distribution. Do Not Release to NTIS

[ Order From Superintendent of Documents, U.S. Government Printing Office, Washington, D.C. 20402.

[X Order From National Technical Information Service (NTIS), Springfield, VA, 2216I
14. NO. OF PRINTED PAGES

70

15. Price 

